NASA Technical Memorandum 106435

AIAA-94-0865

\title{
Comparison of Mixing Calculations for Reacting and Non-reacting Flows in a Cylindrical Duct
}

V.L. Oechsle and H.C. Mongia

Allison Gas Turbine Division

General Motors Corporation

Indianapolis, Indiana

and

J.D. Holdeman

National Aeronautics and Space Administration

Lewis Research Center

Cleveland, Ohio

Prepared for the

32nd Aerospace Sciences Meeting and Exhibit

sponsored by the American Institute of Aeronautics and Astronautics

Reno, Nevada, January 10-13, 1994 


\title{
COMPARISON OF MIXING CALCULATIONS FOR REACTING AND NON-REACTING FLOWS IN A CYLINDRICAL DUCT
}

\author{
V. L. Oechsle* and H. C, Mongia* \\ Allison Gas Turbine Division \\ General Motors Corporation \\ Indianapolis, In 46206 \\ J. D. Holdeman§ \\ National Aeronautics and Space Administration \\ Lewis Research Center \\ Cleveland, $\mathrm{OH} 44135$
}

\begin{abstract}
$\underline{\text { Abstract }}$
A production 3-D elliptic flow code has been used to calculate non-reacting and reacting flow fields in an experimental mixing section relevant to a rich-burn/quick-mix/lean-burn (RQL) combustion system. A number of test cases have been run to assess the effects of the variation in the number of orifices, mass flow ratio and rich-zone equivalence ratio on the flow field and mixing rates. The calculated normalized temperature profiles for the non-reacting flow field agree qualitatively well with the normalized conserved variable isopleths for the reacting flow field indicating that non-reacting mixing experiments are appropriate for screening and ranking potential rapid mixing concepts. For a given set of jet momentum-flux ratio, mass flow ratio, and density ratio (J, MR, and DR), the reacting flow calculations show a reduced level of mixing compared to the non-reacting cases. In addition, the rich-zone equivalence ratio has noticeable effect on the mixing flow characteristics for reacting flows.
\end{abstract}

\section{Nomenclature}

\section{A area \\ $\mathrm{A}_{\mathrm{m}}$ duct crossectional area, also $\mathrm{A}_{\mathrm{tot}}, \mathrm{m}^{2}$ \\ $\mathrm{ACd}$ also $\mathrm{A}_{\mathrm{j}}$, effective orifice area $\mathrm{m}^{2}$}

* AIAA member

\& Senior Research Engineer, AIAA Associate Fellow

Copyright 1992 by V. L. Oechsle. H. C. Mongia, and J. D. Holdeman. No copyright is asserted in the Uniled States under Title 17, U.S. Code. The U.S. Government has the royalty-free licence to exercise all rights under the copyright claimed berein for Government purposes. All other rights are reserved by the copyright owner.
$\mathrm{Ar} \quad$ area ratio (jet/mainstream) $=\mathrm{A}_{\mathrm{j}} / \mathrm{A}_{\mathrm{m}}=\mathrm{ACd} / \mathrm{A}_{\mathrm{m}}$ AMIX area weighted overall $\mathrm{T}$ or $\phi$ deviation from equilibrium, Eq 3

AHOT area weighted T or $\phi$ deviation above equilibrium, Eq 4

ACOLD area weighted $T$ or $\phi$ deviation below equilibrium, Eq 5

B area determined half width of the distribution function

C constant of proportionality between $\sqrt{J}$ and $S / R$, Eq-9

d diameter of the orifice

DR density ratio (jet/mainstream)

DP/P total pressure loss across the mixing wall, \%

f non-dimensional temperature and/or equivalence ratio, Eq 2

$\mathrm{f} / \mathrm{a}$ fuel to air ratio

$\mathrm{j}$ radial vector direction

J momentum-flux ratio (jet/mainstream) $=M^{2} / D R$, also $(\mathrm{MR})^{2} /\left[(\mathrm{DR})\left(\mathrm{A}_{\mathrm{j}} / \mathrm{A}_{\mathrm{m}}\right)^{2}\right]$

$\mathrm{k} \quad$ tangential vector direction

$\mathrm{m}_{\mathrm{tot}} \quad$ overall mixer mass flowrate, $\mathrm{kg} / \mathrm{sec}=\mathrm{m}_{\text {jet }}+$ $\mathrm{m}_{\text {main }}$

M mass flux ratio (jet/mainstream) $=D R V_{\text {jet }}$ $\mathrm{U}_{\text {main }}$

MMIX mass flow weighted overall $\mathrm{T}$ or $\phi$ deviation from equilibrium, Eq 6

MHOT mass flow weighted $\mathrm{T}$ or $\phi$ deviation above equilibrium, Eq-7

MCOLD mass flow weighted T or $\phi$ deviation below equilibrium, Eq-8

MR mass flowrate ratio (jet/mainstream)

n optimum number of orifices / row, Eq-9

P total pressure, atm.

$\mathrm{R}$ radius of the mixing section, $\mathrm{m}$ 
$\mathrm{r}$ radial distance from the centerline of the mixer. $m$

$\mathrm{S} \quad$ orifice spacing in the circumferential direction

$\mathrm{T}$ temperature. $\mathrm{K}$

u local axial velocity, $\mathrm{m} / \mathrm{sec}$

$\mathrm{U}_{\text {main }}$ approach mainstream axial velocity, $\mathrm{m} / \mathrm{sec}$

VR velocity ratio (jet/mainstream) $=\mathrm{V}_{\text {jet }} / \mathrm{U}_{\text {main }}$

$\mathrm{V}_{\text {jet }} \quad$ radial velocity of the jet. $\mathrm{m} / \mathrm{sec}$

w jet width. m. see Fig-3

$\mathrm{x} \quad$ axial distance from the leading edge of the orifice

$\alpha \quad$ parameter used in Eq-2 through 8. can be either temperature or equivalence ratio

$\delta \quad$ value of the cumulative volume fraction at the fequil , Fig-4

$\rho \quad$ fluid density. $\mathrm{kg} / \mathrm{m}^{3}$

$\phi \quad$ equivalence ratio (f/a) local / (f/a) $)_{\text {stoi }}$

\section{$\underline{\text { Subscripts }}$}

$\begin{array}{ll}\text { equil } & \text { equilibrium } \\ \mathrm{j} & \text { jet } \\ \mathrm{m} & \text { mainstream. also (main) } \\ \mathrm{RZ} & \text { rich-zone } \\ \text { stoi } & \text { stoichiometric }\end{array}$

\section{Introduction}

Advanced fuel-efficient commercial turbo propulsion gas turbines pose a number of design challenges for combustion systems including durability, aerothermal performance, wide operability range, and exhaust emissions. Conventional gas turbine combustion system employs a single stage combustion zone which has been optimized to produce low exhaust emissions of carbon monoxide. and unburned hydrocarbons at idle and near-idle operating conditions. Exhaust smoke below the threshold of plume visibility throughout the engine operation range has also been maintained without adversely affecting engine starting, stability, and relight requirement. Moderate reductions in $\mathrm{NO}_{x}$ emissions (up to $30 \%$ ) have been achieved in single-combustion-zone combustors by reducing unmixedness and combustion zone residence time. Further reductions in high-power $\mathrm{NO}_{\mathrm{x}}$ emissions (e.g. up to $50 \%$ from state-of-the-art levels) would require design and development of two-stage combustion concepts including radially or axially staged combustion zones. These types of combustion systems are currently under development.

In order to achieve more demanding ( 70 to $90 \%$ ) $\mathrm{NO}_{\mathrm{x}}$ reduction goals of the advanced turbine engines which will also have considerably higher overall pressure ratios and turbine rotor inlet temperatures. significant advances are needed in the design and development of combustion systems employing multi-staging concepts including lean premix (LPP) and rich burn/quick mix/lean burn (RQL) (Shaw, 1991). The RQL concept studied in-depth by Rizk and Mongia (e.g. Rizk and Mongia, 1990; 1991: 1993) appears to have a number of advantages over other competing ultra-low $\mathrm{NO}_{\mathrm{x}}$ concepts provided one can significantly enhance the mixing during the transition from rich to lean-side combustion. Additional experimental and analytical research effort (e.g. Howe.. et al., 1991; Smith. Talpallikar, and Holdeman, 1991; Talpallikar et al.. 1991; Vranos et al., 1991; Bain. Smith. and Holdeman. 1992. 1993: Liscinsky et al.. 1992; Zhu and Lai. 1992: Doerr and Hennecke, 1993: Liscinsky, True, and Holdeman, 1993) is underway to study and identify the critical design and flow parameters affecting the mixing effectiveness.

An integrated analytical and experimental investigation. between the authors and the UCI Combustion Laboratory has been underway to quantify non-reacting mixing processes in a $80 \mathrm{~mm}$ diameter cylindrical test section, as summarized by Hatch et al.. 1992, Kroll et al.. 1993, and Oechsle. Mongia, and Holdeman. 1992. 1993. These studies have shown that the mixing section effectiveness is affected by the jet-to-mainstream momentum-flux ratio $(\mathrm{J})$, mass flow ratio (MR), and orifice/slot design parameters including R/d, and $\mathrm{S} / \mathrm{d}$, aspect ratio and slot orientation. Here R. $d$. and $\mathrm{S}$ are the radius of the mixing section, orifice diameter, and circumferential spacing between the orifice centers, respectively. The qualitative agreement between predictions and measurements is reasonably good, and the model calculations can be used to provide further insight especially for the flow variables that have not been measured.

A logical question that could be raised is: are the non-reacting mixing investigations appropriate for defining an optimum mixer geometry. This paper summarizes the results of a parallel study to compare the mixing performance of an RQL mixing section in both reacting and non-reacting environments using constant main flow parameters such as jet-to-mainstream momentum-flux ratio $(\mathrm{J})$, mass flow ratio (MR), and density ratio (DR) and establish the difference in the flow field structure. In this study, the mixing effectiveness of a jet in a crosstlow is numerically investigated using a 3-D analytical code. Eight different circular orifice configurations were analyzed in a cylindrical mixing section at $\mathrm{J}=25$ with both 8 and 12 orifices per row. The reacting flow configurations were calculated with mainstream incoming species mole fractions simulating reacting rich-zone equivalent ratios of 1.35 and 1.80. The procedure used to model the geometric configurations was similar to that used by Oechsle, Mongia, and Holdeman, 1992. 1993.

\section{Mathematical Model}

A production 3-D combustor code, COM-3D (Bruce, Mongia, and Reynolds, 1979) is used that solves the turbulent reacting flow transport equations using the SIMPLE algorithm of Patankar and Spalding (Patankar. 1980). This program simulates turbulence by the two-equation $k-\varepsilon$ model (Launder and Spalding. 1974), and combustion following vaporization is determined by a four-step chemical reaction 
model based on Arrhenius and modified eddy breakup concepts. The transport equations for all dependent variables are of the following form as shown in Eq-1:

$\operatorname{div}\left[\rho_{\mathrm{r}} \mathrm{u} \xi-\left(\mu_{\mathrm{eff}} / \mathrm{P}_{\mathrm{r}}\right) \operatorname{grad}(\xi)\right]=\mathrm{S}_{\xi}$

where $\rho_{\mathrm{r}}$ is the mixture density. $u$ is the velocity, $\mu_{\text {eff }}$ is the effective turbulent viscosity. $P_{r}$ is the effective Prandtl/Schmidt number. and $S_{\xi}$ is the source term for the variable $\xi$. The following variables are computed by COM-3D: 1) axial. radial, and swirl velocity components: 2 ) specific enthalpy and temperature; 3 ) turbulence kinetic energy and dissipation rate; 4) unburned fuel, $\mathrm{CO}, \mathrm{H}_{2}$, intermediate fuel, and composite fuel mass fractions; and 5) fuel spray trajectory and evaporation rate.

The computational effort is significantly reduced by modeling a sector of the mixing section comprising a single orifice. Therefore. the shape of the sector was dependent on the number of orifices equally spaced in the circumferential direction. It should be noted that 8 orifices/row yield a computational domain of a 45 degree sector, and similarly, 12 orifices/row yield a 30 degree sector. Periodic boundary conditions were applied in the circumferential direction. No-slip and adiabatic boundary conditions were applied at the outer wall defining the inside wall of the mixing section. Zero-gradient boundary conditions were applied at the center axis. Axial gradients at the exit boundary condition were assumed zero.

\section{$\underline{\text { Geometric Configuration }}$}

In this study, the mixing section was modeled as a constant diameter cylindrical duct with a single row of equally spaced orifices. The outer wall diameter is $80 \mathrm{~mm}$ and the axial length of the mixing section extended from $x / R=-1.4$ to $x / R=6$ where $x$ is referenced from the leading edge of the orifice. Sufficient axial distance was provided both upstream and downstream of the orifice to minimize the impact of the inlet and exit boundary conditions on the calculated flow structure in the primary domain of interest which is $0<x / R<1$. The computational grid domain was typically discretized into 50,000 to 80,000 finite control volumes. The grid was typically denser near the orifice and near the outer wall to resolve the high velocity and temperature gradients resulting from the inlet of the crossflow jet. An orthogonal view of a typical grid arrangement is shown in Figure-1. The grid is normally configured to allow smooth progressive volume change between adjacent control volumes to help speed up the convergence of the solution.

The geometric configurations of the jet orifices is also shown in Figure-1. A total of 8 circular hole configurations were analyzed. Also, it should be noted that the normalized temperature. normalized equivalence ratio, and velocity profile plots shown in this paper depict plane sections in a) the axial-radial plane through the center of the jet from $x / R=-0.5$ to $x / R=2.5$, and $b$ ) the radial-tangential plane at $x / R=1$ (one full mixer radius downstream from the leading edge of the jet). The axial, radial, and tangential directions are shown in Figure-1. It should be noted that the flow direction is from left-to-right in the axial-radial planes and into the paper for the radial-tangential planes.

The overall description of the eight configurations is given in Table-1 and Figure-2. Cases 1. 3, 5, and 7 are for non-reacting flows and the corresponding reacting flow cases are denoted by 2.4 .6 , and 8 . respectively. It is assumed that practical RQL mixing sections will have liner pressure drop and $\mathrm{J}$ approximately $3 \%$ of $\mathrm{P}_{\text {main }}$ and 25 . respectively. The rich-zone equivalence ratio is assumed to lie between 1.35 and 1.80 and lean-zone equivalence ratio is typically 0.45 . It is also assumed that the non-reacting experiment is performed at atmospheric pressure whereas the reacting experiment might be run at high inlet temperature and pressure conditions. It is further assumed that both reacting and non-reacting experiments will be conducted with comparable values of $J$, mass flow ratio (MR), density ratio (DR), area ratio (Ar). and quick mix section liner pressure drop (DP/P).

The eight cases that have been run are for fixed values of $\mathrm{J}=25: \mathrm{MR}=1.83$ and 2.67: corresponding to rich-zone equivalence ratio, $\phi_{R Z}=1.35$ and 1.80 , and other variables listed in Table-1. The blockage is defined as the circumferential projection of the orifice divided by the spacing between the orifice centers. Typically 150 to 200 finite control volume nodes were used to simulate the orifice.

The reacting flow conditions, the operating pressure and temperature simulated realistic gas turbine operating conditions ( $\mathrm{P}=13.4 \mathrm{~atm} ., \mathrm{T}=978 \mathrm{~K})$. The mainstream flow and jet flow conditions are show in Table- 1 . The incoming mainstream species mole fractions for $\left(\mathrm{CO}, \mathrm{CO}_{2} \cdot \mathrm{H}_{2} \mathrm{O}\right.$, and $\left.\mathrm{H}_{2}\right)$ were determined based on the given rich-zone equivalence ratio (see Table-1) at equilibrium at the prescribed operating conditions using JP-5 for the typical fuel properties. Although this assumption may not be totally realistic in an operating RQL rich section. it does provide a baseline for comparison. It is recognized that the rich-zone will produce a great amount of $\mathrm{CO}$ and unburned hydrocarbons which are directly admitted to the mixing region. This will probably increase the reaction in the mixing zone prompted by the mixture with the additional air. However, since the rich-zone performance greatly depends on the residence time and geometric parameters, and since its design is not within the scope of this study, the assumed rich-zone performance (achieving chemical equilibrium) is a reasonable initial condition towards analyzing the reaction in the mixing zone. The four specified species used in the inlet mainstream condition correspond to the four-step chemical reaction used in COM-3D. The species mole fractions, temperature. and velocity profiles were assumed to be uniform across the inlet cross-section of the mixing section. The jet-to-mainsteam mass flow ratio was determined by the prescribed lean zone 
equivalence ratio of 0.45 (which is constant for all reacting flow configurations reported herein). The air jet flow was characterized by a radial. uniform flow across the orifice effective area. The assumption of uniform mass injection/area is applied in the mathematical model in all the analyzed configurations.

The non-reacting configuration models were setup for typical atmospheric temperature and pressure conditions $\left(\mathrm{T}_{\text {jet }}=\right.$ $300 \mathrm{~K}, \mathrm{P}=1 \mathrm{~atm}$.) for which the mainstream inlet flowrate was varied to obtain the same J, MR. DR. orifice ACd, and DP/P as the comparable reacting flow case. Note that in the actual optimization process, slight variations in the density ratio were obtained as shown in Table- 1 .

The turbulence kinetic energy of the mainstream and jet flows were $0.3 \%$ of the square of the mean velocities. The turbulence length scales of the mainstream tlow were $2 \%$ of the mixer diameter, and the turbulence length scale of the jet was of the order of the orifice diameter. The inlet conditions for all orifices in the mixing section were equal to create a symmetrical input condition about the circumferential direction which was necessary for the sector analysis.

A typical numerical solution took about 250 iterations for full convergence with overall mass flow residuals of $0.05 \%$ of the total mixing section mass flowrate. All solutions were obtained using the Cray Y-MP and a typically converged solution took about 1 to $1.5 \mathrm{hrs}$ of CPU time. The reacting flow solutions consumed about twice the CPU time due to the additional species variables which are solved in the model.

\section{$\underline{\text { Results and Discussion }}$}

The mixing performance for all configurations analyzed in this study were ultimately evaluated at $x / R=1$. It is however recognized that the mixing performance throughout the mixing section volume of interest $(0 \leq x / R \leq 1)$ should also be considered since complex structures are present in the flow field especially near the entry of the jet.

Two different methods were used to analyze the numerical results:

1) the results were analyzed qualitatively by visual observation of the temperature, equivalence ratio, and velocity field solutions. The temperature and equivalence ratio results are presented as normalized values with respect to the overall differential between the mainstream flow and the jet flow inlet temperatures and equivalence ratios consecutively. This normalized parameter ( $\mathrm{f}$ ) is defined in Eq-2 where $\alpha=$ temperature or equivalence ratio.

$$
f=\frac{\alpha_{j k}-\alpha_{\text {jet }}}{\alpha_{\text {main }}-\alpha_{\text {jet }}}
$$

The value of (f) varies from 0 to 1 , where 0 is the value of the unmixed jet and 1 is the value of the mainstream flow. Note that $\mathrm{f}=1-\theta$. where $\theta$ is as defined previously (Holdeman. 1993) and used elsewhere also. It is also important to note that the definition of (f) also applied for the normalized equivalence ratio in the reacting flow configurations where $\mathrm{f}=1$ equals the rich-zone equivalence ratio and $\mathrm{f}=0$ is the jet equivalence ratio. The definition of (f) however does not apply to the temperature distribution in the reacting flow solutions since the temperature in some areas of the mixing . region rise above that of the incoming mainstream flow due to the chemical reaction of the rich-zone exit composition. The value of the equilibrium temperature (as applied to the non-reacting conditions) and equilibrium equivalence ratio (applied to the reacting conditions) based on the normalized definition parameter (f) in Eq-1 are also equivalent since both are conserved variables. Both equilibrium values were calculated in a purely adiabatic system at any location downstream of the jet injection.

In addition to the temperature and equivalence ratio distribution plots. the velocity plots in the axial-radial plane through the orifice center are shown for all configurations for $x / R$ from -0.5 to 2.5 . In each plot, the streamlines corresponding to the developing jet in the mixing section are shown depicting the jet penetration and jet width. The values of the jet width (w) and mean jet penetration evaluated at $x / R=0.625$. 1 , and 2 are tabulated in Table-2 and the pictorial definition of both of these parameters is shown in Figure-3. The jet penetration at $x / R=2$ is shown only for the purpose to establish if complete penetration is obtained at $\mathrm{x} / \mathrm{R}=1$.

2) Three different statistical methods are reported in this paper:

a) The performance of the mixing section at the radial-tangential planes at $x / R=1$ was quantified by using area weighted planar deviation parameters. The smallest deviation indicates the best mixing configuration. Three different parameters (mixing deviations) AMIX. AHOT, and ACOLD are described in Eq-3 through Eq-5. Note that AMIX also equals the square root of the sum of the squared values of both AHOT and ACOLD. It is also important to note that the definitions in Eq-3 through Eq-5 do not correct the mixing non-uniformity for the bias introduced in the region of the section where the air is being injected through the orifice. This is accepted since the comparison between . the reacting and non-reacting results is only performed at $\mathrm{x} / \mathrm{R}=1$ which is downstream of the trailing edge of all orifices. The area-weighted non-uniformity results are shown in Table-3. 


$$
\begin{aligned}
& \text { AMLX }=\left[\frac{1}{A_{\text {tot }}} \sum_{j \mathrm{k}} \mathrm{A}_{\mathrm{jk}}\left[\frac{\alpha_{\mathrm{jk}}-\alpha_{\mathrm{eq}}}{\alpha_{\text {main }}-\alpha_{\mathrm{jet}}}\right]^{2}\right]^{1 / 2} \\
& \text { AHOT }=\left[\frac{1}{\mathrm{~A}_{\mathrm{tot}}} \sum_{\mathrm{jk}} \mathrm{A}_{\mathrm{jk}}\left[\frac{\alpha_{\mathrm{jk}}-\alpha_{\mathrm{eq}}}{\alpha_{\text {main }}-\alpha_{\mathrm{jet}}}\right]^{2}\right]^{1 / 2} \text { for } \alpha_{j \mathrm{k}}>\alpha_{\mathrm{eq}} \\
& \mathrm{ACOLD}=\left[\frac{1}{\mathrm{~A}_{\mathrm{tot}}} \sum_{\mathrm{jk}} \mathrm{A}_{\mathrm{jk}}\left[\frac{\alpha_{\mathrm{jk}}-\alpha_{\mathrm{eq}}}{\alpha_{\text {main }}-\alpha_{\mathrm{jet}}}\right]^{2}\right]^{1 / 2} \text { for } \alpha_{j \mathrm{k}}<\alpha_{\mathrm{eq}}
\end{aligned}
$$

b) Mass flow weighted planar deviation parameters (also evaluated at $x / R=1$ ) as defined in Eq- 6 through Eq-8 were also used to evaluate the mixing region. The MMIX value also equals the square root of the sum of the squared values of both MHOT and MCOLD. Note that these parameters are essentially the same as the area weighted parameters with the added density and velocity weighting terms.

$$
\begin{aligned}
& \operatorname{MMIX}=\left[\frac{1}{\dot{m}_{\mathrm{tot}}} \sum_{\mathrm{jk}} \mathrm{A}_{\mathrm{jk}} \rho_{\mathrm{jk}} \mathrm{u}_{\mathrm{jk}}\left[\frac{\alpha_{\mathrm{jk}}-\alpha_{\mathrm{eq}}}{\alpha_{\mathrm{man}}-\alpha_{\mathrm{jet}}}\right]^{2}\right]^{1 / 2} \\
& \text { MHOT }=\left[\frac{1}{\dot{\mathrm{m}}_{\mathrm{tot}}} \sum_{\mathrm{jk}} \mathrm{A}_{\mathrm{jk}} \rho_{\mathrm{jk}} \mathrm{u}_{\mathrm{jk}}\left[\frac{\alpha_{\mathrm{jk}}-\alpha_{\mathrm{eq}}}{\alpha_{\mathrm{msin}}-\alpha_{\mathrm{jet}}}\right]^{2}\right]^{1 / 2} \text { for } \alpha_{\mathrm{jk}}>\alpha_{\mathrm{eq}} \\
& \operatorname{MCOLD}=\left[\frac{1}{m_{\mathrm{tot}}} \sum_{\mathrm{jk}} \mathrm{A}_{\mathrm{jk}} \rho_{\mathrm{jk}} \mathrm{u}_{\mathrm{jk}}\left[\frac{\alpha_{\mathrm{jk}}-\alpha_{\mathrm{eq}}}{\alpha_{\text {main }}-\alpha_{\mathrm{jet}}}\right]^{2}\right]^{1 / 2} \text { for } \alpha_{\mathrm{jk}}<\alpha_{\mathrm{eq}}
\end{aligned}
$$

c) The flow field was also evaluated by performing a numerical volume integration throughout the mixing section of interest. The volume integration parameters allow the quantification of the entire flow field mixture which is more descriptive of the overall flow phenomena in the mixing section as compared to a planar deviation analysis as performed with the mass flow weighted and area weighted parameters. This volume integration was performed on the temperature or equivalence ratio distributions depending if the configuration analyzed was either non-reacting or reacting respectively. The entire range of the normalized parameter $\mathrm{f}$ (from 0 to 1 ) was sub-divided into 200 equal size bins and the volume of the computational control volumes corresponding to the value of $(f)$ at a certain bin size ( $f_{i}$ to $f_{i}+\Delta f$ ) was integrated. The integrated volume in each bin was normalized based on the entire analyzed mixer volume. thus obtaining the normalized volume fraction. The volume fraction for each bin was plotted in the ordinate with the corresponding value of $\mathrm{f}$ in the abscissa forming a histogram plot. In addition, the incremental partial volume per bin was integrated from $\mathrm{f}=0$ to 1 and the cumulative volume fraction was obtained for all the 8 analyzed configurations. The cumulative volume fraction is also plotted versus (f) for all configurations. Note that the cumulative volume fraction shown in this paper is the integrated histogram for $(0 \leq f \leq 1)$. Therefore this value is generally independent of the bin size used in this analysis. Although not compared in this paper, the cumulative volume fraction for the interval $f_{\text {equil }} \pm \Delta f$ may be used to quantify the mixing uniformity within the tolerance $\Delta \mathrm{f}$. In this paper however, the cumulative volume fraction is only used to indicate whether the histograms indeed integrate to a value of 1 , as expected. The shape of the volume fraction histogram was also characterized by the definition of $\mathrm{B}(+)$ and $\mathrm{B}(-)$ similar to that used by (Oechsle. Mongia, and Holdeman. 1992). The value of $\mathrm{B}(+)$ is the "area determined" distribution half width above $\mathrm{f}_{\text {equil }}$ such that the integrated area under the histogram above $\mathrm{f}_{\text {equil }}$ is $1 / 2$ that of the overall histogram area above $f_{\text {equil. }}$ The same applies to $\mathrm{B}(-)$ for the area below $\mathrm{f}_{\text {equil }}$. The definitions of $\mathrm{B}(+)$ and $\mathrm{B}(-)$ are shown pictorially in Figure -4 . The best mixing results yield $\mathrm{B}(+)=\mathrm{B}(-)=0$, meaning that the histogram distribution width effectively collapses towards the equilibrium value of ( $f$ ) due to a homogeneous mixture of either temperature or equivalence ratio.

The results in this paper are presented in the following manner:

a) effect of reaction on mixing

b) effect of number of orifices/row on mixing, and

c) effect rich-zone equivalence ratio on mixing

\section{Effect of reaction on mixing}

The normalized temperature distribution results for all configurations for the axial-radial plane sections through the center of the jet are shown in Figure-5. The corresponding radial-tangential planes at $x / R=1$ are shown in Figure- 6 . Significant differences are apparent in the temperature distribution for the same configuration with similar operating conditions for both reacting and non-reacting cases. Note that the approach flow normalized temperature in the reacting flow cases is not the maximum value in the mixing section since the latter depends on the rich-zone equivalence ratio and is therefore not a conserved scalar. A lower approach mainstream normalized temperature value is expected with higher rich-zone equivalence ratio. These major differences are attributed to the fact that the reacting flow configurations are not only mixing hot and cold jets but also chemically reacting in areas permissible by the chemical kinetics of the species exiting the rich-zone of the combustor. It is worth noting that significant reaction occurs behind the orifice where the jet wake produces a low velocity recirculation between hot rich mixture exiting the rich-zone and relatively cold jets. This observation is shown for configuration \# 2 and 4 (Figure-5b, 5d, 6b, and 6d) especially since both configurations have only 8 orifices. The configurations \# 6 and 8 (Figure-5f, 5h, 6f, and 6h) however have 12 holes/row thus producing a much smaller jet trailing wake and therefore significantly inhibiting this reaction in the 
mixing section. Note that the jet penetration for 8 orifices is greater than for 12 orifices and this is discussed later in more detail. The non-reacting flow fields are similar to the results reported by Oechsle. Mongia, and Holdeman 1992, and 1993. Note that in Figures -5 and $6, \mathrm{f}=1$ applies to the approach mainstream normalized temperature in the non-reacting flow configurations. Similarly, the stoichiometric temperature in the reacting flow configurations has a value of 1 .

The normalized temperature distribution (f) in the non-reacting flows compare well with the normalized equivalence ratio distribution for all the configurations in Figures-7 and 8 . These results seem to indicate that non-reacting temperature profiles can emulate the reacting flow mass flow distribution reasonably well. It is worth noting that the non-reacting jets appear to interact more at the center of the mixer at about $x / R=0.5$ as compared to the reacting flow jets. see (Figure-7a. 7b). This interaction is usually spotted by the upstream swirling flow produced at the location where opposing jets merge thereby inducing extra mixing between the mainstream and jet. This was not observed for the 12 orifice/row configurations due to shallow jet penetration produced by the 12 orifice/row configurations. Note that in Figure -7 and $8, \mathrm{f}=0$ represents the jet normalized temperature (non-reacting flow), and $\mathrm{f}=1$ represents the mainstream normalized temperature (non-reacting flow).

The planar statistical variances indicate very similar conclusions to the observed temperature and equivalence ratio distributions. The area weighted and mass flow weighted parameters in Table-3 indicate very similar mixing non-uniformities between reacting and non-reacting cases for the same $J, M R$ and $D R$ at $x / R=1$. These results are also shown graphically in Figure-9a and $9 \mathrm{~b}$. The results indicate that the non-reacting flow configurations mix better compared to the reacting flow counterparts. Both area weighted and mass flow weighted results indicate similar results as shown previously in Oechsle. Mongia, and Holdeman, 1993. The volume fraction histogram results for all the configurations are shown in Figures-9c. 10, and 11. The $\mathrm{B}(+)$ and $\mathrm{B}(-)$ half width parameters are also tabulated in Table- 3 and both indicate somewhat similar conclusions to the area weighted and mass flow weighted parameters; however, the differences between the volume fraction histogram shapes for reacting vs. non-reacting flow configurations with similar geometry and operating conditions are plotted in Figure-12. The results shown in Figure-12 indicate that for all comparable configurations the cumulative difference of the volume fraction/bin amounts from $50 \%$ to about $70 \%$ of the overall mixer volume of interest see Figure-12a, 12d. This observation is of significant value since particular mixing flow configurations may compare well at $\mathrm{x} / \mathrm{R}=1$ using both visually and planar average methodologies at $x / R=1$ but may be significantly different throughout the mixing section as shown by the volume integral results. This observation may have a significant effect on the future use of non-reacting flow configuration analysis when selecting a good mixing configuration for low $\mathrm{NO}_{\mathrm{x}}$ application.
The penetration of the jet for both reacting and non-reacting configurations are tabulated in Table- 2 and the results are shown in Figure-13. The results indicate very little difference in both the penetration of the jet core and the jet width at $x / R$ of $0.625,1$, and 2 . It is important to note that although the change in the jet width is small according to the results shown in Table-2. the temperature and equivalence ratio cores of the jet as shown in Figure- 6 and 8 for the reacting cases are significantly different compared to the non-reacting cores (noting that J, MR. and DR in the comparison are . constant). Both temperature and equivalence ratio cores of the jet are significantly preserved throughout the flowfield up to $x / R=1$ for the reacting flow calculations only.

\section{Effect of the number of orifices/row on mixing}

The effect of the number of orifices/row on mixing has the expected results for constant $\mathrm{J}$ conditions. The results in Table- 2 quantify the decrease in jet penetration with the increase in the number of jets as shown in Figure-13. Note that the streamlines depicted in Figure-13 indicate almost full turning of the jet by $\mathrm{x} / \mathrm{R}=1$ and these results correlate well with the temperature and equivalence ratio distribution plots indicating minor developments in the mixing flow field beyond $x / R=1$. The temperature and equivalence ratio profiles however indicate that enhanced mixing is obtained with the increase in the number of orifices for a given value of $\mathrm{J}$ as reported previously by Oechsle, Mongia, and Holdeman. (1992). The results obtained with the area weighted. mass flow weighted, and histogram parameters $\mathrm{B}(+)$ and $\mathrm{B}(-)$ indicate this same conclusion. The difference in the histograms between 8 and 12 orifices/row at similar J. MR and DR conditions are shown in Figure-14. Note that the histograms differ significantly in regions near $\mathrm{f}_{\text {equil }}$ (Figure-14c and $14 \mathrm{~d}$ ). The reacting flow configurations (Fig-14b and 14d) show slightly less difference in mixing between 8 and 12 holes/row (with cumulative $\Delta$ vol values of about $50 \%$ ) as compared to the non-reacting configurations (Fig-14a. and $14 \mathrm{c}$ with $\Delta$ vol values in excess of $60 \%$ ).

As the number of holes increases, the jet wake volume decreases and therefore prevents the hot mainstream gas from entering and occupying this volume and reacting with cold jet stream which is recirculated in this wake. Both reacting and non-reacting results appear to be sensitive to the size of this jet trailing wake region as mentioned previously in this paper. The best mixing configuration from the 8 cases reported in this paper is the configuration number 7 shown in Figures $-7 \mathrm{~g}, 8 \mathrm{~g}$, and $11 \mathrm{c}$. Note that the optimum mixer for a nominal $\mathrm{J}=25$ is 9 holes/row as calculated in Eq-9 (Holdeman. 1993), where $\mathrm{n}$ is the number of orifices and $\mathrm{C}=2.5$.

$\mathrm{n}=\frac{\pi \sqrt{2 \mathrm{~J}}}{\mathrm{C}}$ 
Effect of the rich-zone equivalence ratio on mixing

The effect of the increase of the rich-zone equivalence ratio $\left(\phi_{\mathrm{RZ}}\right)$ from 1.35 to 1.80 is shown in Figures-5b, 5d, 6b, and $6 \mathrm{~d}$ (temperature profiles) and Figures-7b, 7d, 8b, and 8d (equivalence ratio profiles). Significant differences in the temperature flow field are noted with the increase in rich-zone equivalence ratio. With a $\phi_{\mathrm{RZ}}=1.35$, the flow entering the mixing section need only mix slightly with the jet air to allow stoichiometric f/a to increase the temperature due to the expected chemical kinetics. However, the $\phi_{R Z}$ $=1.80$ configurations require a longer time to allow mixing of the rich mixture entering the mixing section, and the residence time of the mixing section limits the amount of further reaction occurring in the mixer. Therefore the temperature profiles are different as compared to the $\phi_{\mathrm{RZ}}=1.35$ configurations. This effect can be somewhat beneficial in the design of an RQL combustor since the $\phi_{R Z}$ appears to limit the location of the reaction between the rich mainstream flow and dilution jet mixing. thus allowing the designer to delay the reaction process after adequate mixing has been obtained in the mixing section. The difference in the amount of reaction in the mixing section is clearly shown in Figure-5f and $5 \mathrm{~h}$ for $\phi_{\mathrm{R} Z}$ of 1.35 and 1.80 consecutively. In addition to the delayed reaction produced by increased in $\phi_{\mathrm{RZ}}$. the mixing flowfield is slightly enhanced (see the results of configurations 1 and 3,2 and 4. 5 and 7. and 6 and 8). Note that the volume histograms cannot be compared for in this case since the $\mathrm{f}_{\text {equil }}$ is a function of the $\phi_{\mathrm{RZ}}$.

\section{Conclusions}

1) The parameter (f) based on the non-reacting temperature profiles does not compare with the reacting flow normalized temperature solutions due to the additional reaction occurring in the mixing zone. The (f) parameter based on temperature and equivalence ratio however shows similar flow field solutions for non-reacting and reacting flows (respectively) since both are conserved scalar quantities.

2) The jet interaction between opposing jets becomes more significant for non-reacting flows calculations as compared to reacting flow results however. jet penetration itself appears not to have been significantly affected. The core of the jet appears to diffuse less and has less overall mixing in the reacting flow solutions as compared to the non-reacting cases.

3) All three statistical parameters, area weighted, mass flow weighted, and histogram half widths correlate well for the selection of the best mixing configuration (configuration \#7). Significant differences are shown in the histogram shapes between reacting and non-reacting flows that are not shown using simple planar statistical parameters. This indicates that additional study is necessary to evaluate the use of planar averages in characterizing the mixing flow phenomena. and in particular. extrapolating the expected $\mathrm{NO}_{\mathrm{x}}$ formation in a mixing section of an RQL combustor based on results valued at $\mathrm{x} / \mathrm{R}=1$.

4) Increase in the number of orifices decreases the overall volume of the wake behind each jet and therefore significantly affects the reaction in this area. The wake region behind the jet is an optimum location for flame stability due to low velocity recirculation areas where mainstream rich fuel mixture is mixed with relatively cold jet air to enhance reaction.

5) An increase in rich-zone equivalence ratio $\left(\phi_{R Z}\right)$ produces an effective reaction delay in the mixing section; therefore. the selection of the appropriate $\phi_{\mathrm{RZ}}$ allows the combustor designer to delay this mixing zone reaction sufficiently to allow adequate mixing to occur.

\section{Acknowledgements}

This work was supported by NASA Contract NAS3-25950. Task Order \# 1

\section{$\underline{\text { References }}$}

Bain. D.B.. Smith, C.E.. and Holdeman. J.D.,"CFD Mixing Analysis of Jets Injected from Straight and Slanted Slots into Confined Crossflow in Rectangular Ducts," AIAA paper No. 92-3087 (1992). (Also NASA TM 105699).

Bain. D.B.. Smith. C.E.. and Holdeman. J.D.."Parametric CFD Analysis of Jet Mixing into Confined Crossflow in Rectangular Ducts." AIAA paper No. 93-2044 (1993). (Also NASA TM 106179).

Bruce. T.W.. Mongia. H.C.. and Reynolds. R.S.. "Combustion design criteria validation," (1979), (USARTL-TR-78-55A. B. and C).

Doerr, Th.. and Hennecke, D.K., " The Mixing Process in the Quenching Zone of the Rich-Lean-Combustion Concept." AGARD-PEP 81st Sympossium of Fuels and Combustion Technology for Advanced Aircraft Engines, (1993).

Hatch. M.S.. Sowa. W.A.. Samuelsen. G.S.. and Holdeman. J.D.. "Jet Mixing Into a Heated Cross Flow in a Cylindrical Duct: Influence of Geometry and Flow Variations." AIAA Paper No. 92-0773 (1992). (Also NASA TM 105390).

Holdeman. J.D., "Mixing of Multiple Jets with a Confined Subsonic Crossflow." Prog. Energy Combust. Sci., (1993), Vol 19. pp 31-70. (Also see AIAA Paper No. 91-2458 (1991), and NASA TM 104412).

Howe, G.W.. Li. Z.. Shih. T.I.-P.. and Nguyen. H.L.."Simulation of mixing in the quick quench region of a rich burn - 
quick quench mix - lean burn combustor." AIAA Paper No. 91-(0410 (191).

Kroll. J.T., Sowa, W.A., Samuelsen, G.S., and Holdeman, J.D.."Optimization of Circular Orifice Jets Mixing into a Heated Crossflow in a Cylindrical Duct," AIAA Paper No. 93-0249 (1993).

Launder. B.E., and Spalding. D.B.." Lectures in Mathematical Models of Turbulence." Academic Press Inc. (London) LTD.. (1972).

Liscinsky. D.S.. True. B.. Vranos. A.. and Holdeman. J.D.. "Experimental Study of Cross-Stream Mixing in a Rectangular Ducts." AIAA Paper No. 92-3090 (1992). (Also NASA TM 106194).

Liscinsky. D.S.. True. B.. and Holdeman. J.D.. "Experimental Investigation of Crossflow Jet Mixing in a Rectangular Duct." AIAA Paper No. 93-2037 (1993). (Also NASA TM 106152).

Oechsle. V.L., Mongia, H.C., and Holdeman, J.D. " A Parametric Numerical Study of Mixing in a Cylindrical Duct." AIAA Paper No. 92-3088 (1992). (Also NASA TM 105695).

Oechsle, V.L., Mongia, H.C., and Holdeman, J.D. " An Analytical Study of Jet Mixing in a Cylindrical Duct." AIAA Paper No. 93-2043 (1993). (Also NASA TM 106181).

Patankar.S.V.. " Numerical Heat Transfer and Fluid Flows." Hemisphere. Washington D.C. (1980).

Rizk. N.K.. Mongia. H.C.. "Ultra-Low NO $\mathrm{N}_{\mathrm{x}}$ Rich Lean Combustion." ASME Paper No. 90-GT-87 (1990)).

Rizk. N.K.. Mongia. H.C.. "Low NO $\mathrm{x}$ Rich-Lean Combustion Concept Application." AIAA Paper No. 91-1962 (1991).

Rizk, N.K., Mongia, H.C.. "Three-Dimensional NOx Model for Rich/Lean Combustor." AIAA Paper No. 93-0251 (1993).

Shaw. R.J.. "Engine Technology Challenges for a 21st Century High Civil Speed Transport." AIAA 10th International Symposium on Air Breathing Engines (1991). (Also NASA TM 104361).

Smith. C.E.. Talpallikar, M.V., and Holdeman, J.D.,"A CFD Study of Jet Mixing in Reduced Flow Areas for Lower Combustion Emissions." AIAA Paper No. 91-2460 (1991). (Also NASA TM 104411).

Talpallikar, M.V.. Smith. C.E., Lai. M.C.. and Holdeman. J.D.. " CFD Analysis of Jet Mixing in Low $\mathrm{NO}_{x}$ Flametube Combustors." J. Eng. Gas Turbine Pwr. 114. 416 (1992). (Also ASME Paper No. 91-GT-217; NASA TM 104466).
Vranos. A., Liscinsky, D.S.. True. B.. and Holdeman. J.D.." Experimental Study of Cross-Stream Mixing in a Cylindrical Duct." AIAA Paper No. 91-2459 (1991). (Also NASA TM 105180).

Zhu, G., and Lai, M.-C.. "A parametric study of penetration and mixing of radial jets in necked-down cylindrical crossflow," AIAA Paper No. 92-3091 (1992). 


\begin{tabular}{|c|c|c|c|c|c|c|c|c|c|}
\hline CASE & Units & 1 & 2 & 3 & 4 & 5 & 6 & 7 & 8 \\
\hline \multicolumn{10}{|l|}{ OVERALL } \\
\hline $\mathrm{J}($ jet/main) & & 25.0 & 25.0 & 25.0 & 25.0 & 25.0 & 25.0 & 25.0 & 25.0 \\
\hline MR (jet.main) & & 1.83 & 1.83 & 2.67 & 2.67 & 1.83 & 1.83 & 2.67 & 2.67 \\
\hline DR (jet/main) & & 2.578 & 2.584 & 2.300 & 2.231 & 2.578 & 2.584 & 2.300 & 2.231 \\
\hline VR (jet/main) & & 3.114 & 3.110 & 3.297 & 3.347 & 3.114 & 3.110 & 3.297 & 3.347 \\
\hline Ar (jet/main) & & 0.228 & 0.228 & 0.352 & 0.358 & 0.228 & 0.228 & 0.352 & 0.358 \\
\hline Phi (rich zone) & & 0.00 & 1.35 & 0.00 & 1.80 & 0.00 & 1.35 & 0.00 & 1.80 \\
\hline Phi (lean zone) & & 0.00 & 0.45 & 0.00 & 0.45 & 0.00 & 0.45 & 0.00 & 0.45 \\
\hline $\mathrm{DP} / \mathrm{P}$ & $\%$ & 2.91 & 3.08 & 3.00 & 3.10 & 3.00 & 3.00 & 3.00 & 3.10 \\
\hline \multicolumn{10}{|l|}{ MAINSTREAM } \\
\hline$P$ main & atm. & 1.0 & 13.4 & 1.0 & 13.4 & 1.0 & 13.4 & 1.0 & 13.4 \\
\hline $\mathrm{T}$ main & $\mathbf{K}$ & 773 & 2,527 & 690 & 2,182 & 773 & 2,527 & 690 & 2,182 \\
\hline$V_{\text {main }}$ & $\mathrm{m} / \mathrm{sec}$ & 22.7 & 42.3 & 21.8 & 39.4 & 23.1 & 41.7 & 21.8 & 39.4 \\
\hline$M$ main & $\mathrm{kg} / \mathrm{sec}$ & 0.052 & 0.399 & 0.056 & 0.431 & 0.045 & 0.393 & 0.056 & 0.430 \\
\hline Mixer Diameter & m & 0.080 & 0.080 & 0.080 & 0.080 & 0.080 & 0.080 & 0.080 & 0.080 \\
\hline JET & & Circular & Circular & Circular & Circular & Circular & Circular & Circular & \begin{tabular}{|l|} 
Circular \\
\end{tabular} \\
\hline$P$ jet & atm. & 1.0 & 13.4 & \begin{tabular}{|l|}
1.0 \\
\end{tabular} & 13.4 & \begin{tabular}{|l|}
1.0 \\
\end{tabular} & 13.4 & \begin{tabular}{|l|}
1.0 \\
\end{tabular} & 13.4 \\
\hline$T$ jet & $\mathbf{K}$ & 300 & 978 & 300 & 978 & 300 & 978 & 300 & 978 \\
\hline V jet & $\mathrm{m} / \mathrm{sec}$ & 70.8 & 131.7 & 71.9 & 131.9 & 71.9 & 129.8 & 71.9 & 131.9 \\
\hline $\mathbf{M}$ jet & $\mathrm{kg} / \mathrm{sec}$ & 0.096 & \begin{tabular}{|l|}
0.731 \\
\end{tabular} & 0.150 & 1.150 & \begin{tabular}{|l|}
0.083 \\
\end{tabular} & 0.720 & 0.150 & 1.149 \\
\hline ACd jet/row & $\mathrm{m}^{2}$ & $1.15 \mathrm{e}-(03$ & $1.14 \mathrm{e}-03$ & $1.77 \mathrm{e}-03$ & $1.80 \mathrm{e}-03$ & $1.15 \mathrm{e}-03$ & $1.14 \mathrm{e}-03$ & $1.77 \mathrm{e}-03$ & $1.80 \mathrm{e}-03$ \\
\hline Orifice Cd & & 0.80 & \begin{tabular}{|l|}
0.81 \\
\end{tabular} & \begin{tabular}{|l|}
0.80 \\
\end{tabular} & \begin{tabular}{|l|}
0.82 \\
\end{tabular} & \begin{tabular}{|l|}
0.80 \\
\end{tabular} & \begin{tabular}{|l|}
0.80 \\
\end{tabular} & 0.80 & \begin{tabular}{|l|}
0.82 \\
\end{tabular} \\
\hline Number of orifices & & 8 & 8 & 8 & 8 & 12 & 12 & 12 & 12 \\
\hline Blockage & & 0.430 & 0.430 & 0.534 & 0.538 & 0.527 & 0.526 & 0.654 & 0.659 \\
\hline Orifice T.E. $\mathrm{x} / \mathbf{R}$ & & 0.338 & 0.338 & 0.420 & 0.423 & 0.276 & 0.276 & 0.343 & 0.345 \\
\hline Flow Condition & & NR & REACT & NR & REACT & NR & REACT & NR & REACT \\
\hline
\end{tabular}

Table-1. Overall description of the operating conditions and geometric configurations

\begin{tabular}{|c|c|c|c|c|c|c|}
\hline \multirow{2}{*}{ Conf } & \multicolumn{2}{|c|}{ Jet Penetration $(\omega) \mathrm{x} / \mathrm{R}=0.625$} & \multicolumn{2}{|c|}{ Jet Penetration @ $\mathrm{x} / \mathrm{R}=1.0$} & \multicolumn{2}{c|}{ Jet Penetration $@ \mathrm{x} / \mathrm{R}=2.0$} \\
\cline { 2 - 7 } & $\mathrm{w} / \mathrm{R}$ & Penetration of jet core/ $/ \mathrm{R}$ & w/R & Penetration of jet core/ $/ \mathrm{R}$ & w/R & Penetration of jet core/R \\
\hline 1 & 0.425 & 0.7 & 0.35 & 0.75 & 0.325 & 0.75 \\
\hline 2 & 0.4 & 0.675 & 0.35 & 0.725 & 0.325 & 0.725 \\
\hline 3 & 0.475 & 0.625 & 0.45 & 0.675 & 0.375 & 0.7 \\
\hline 4 & 0.475 & 0.575 & 0.425 & 0.625 & 0.35 & 0.675 \\
\hline 5 & 0.325 & 0.575 & 0.325 & 0.625 & 0.3 & 0.65 \\
\hline 6 & 0.35 & 0.575 & 0.325 & 0.625 & 0.3 & 0.65 \\
\hline 7 & 0.425 & 0.55 & 0.4 & 0.6 & 0.375 & 0.6 \\
\hline 8 & 0.425 & 0.5 & 0.425 & 0.55 & 0.375 & 0.575 \\
\hline
\end{tabular}

Table-2. Jet penetration development through the center of the jet in the circumferential direction

\begin{tabular}{|c|c|c|c|c|c|c|c|c|c|c|c|c|}
\hline Config & condition & \# holes & PHI RZ & MR & AMIX & AHOT & ACOLD & MMIX & MHOT & MCOLD & B $(-)$ & B $(+)$ \\
\hline 1 & NR & 8 & 0 & 1.83 & 0.21 & 0.187 & 0.096 & 0.223 & 0.195 & 0.108 & 0.171 & 0.266 \\
\hline 2 & REACT & 8 & 1.35 & 1.83 & 0.221 & 0.191 & 0.111 & 0.223 & 0.195 & 0.108 & 0.182 & 0.333 \\
\hline 3 & NR & 8 & 0 & 2.67 & 0.173 & 0.154 & 0.079 & 0.184 & 0.162 & 0.085 & 0.148 & 0.255 \\
\hline 4 & REACT & 8 & 1.8 & 2.67 & 0.201 & 0.175 & 0.1 & 0.209 & 0.178 & 0.109 & 0.179 & 0.328 \\
\hline 5 & NR & 12 & 0 & 1.83 & 0.164 & 0.144 & 0.079 & 0.165 & 0.138 & 0.091 & 0.157 & 0.207 \\
\hline 6 & REACT & 12 & 1.35 & 1.83 & 0.171 & 0.144 & 0.093 & 0.171 & 0.132 & 0.108 & 0.166 & 0.244 \\
\hline 7 & NR & 12 & 0 & 2.67 & 0.144 & 0.13 & 0.062 & 0.139 & 0.118 & 0.074 & 0.136 & 0.169 \\
\hline 8 & REACT & 12 & 1.8 & 2.67 & 0.166 & 0.142 & 0.082 & 0.164 & 0.131 & 0.098 & 0.159 & 0.288 \\
\hline
\end{tabular}

Table-3. Summary of the mixing non-uniformity resuits for all the analyzed configurations

NOTE: REACT $=$ Reacting flow,$N R=$ Non-reacting flow, PHI RZ = rich-zone equivalence ratio 

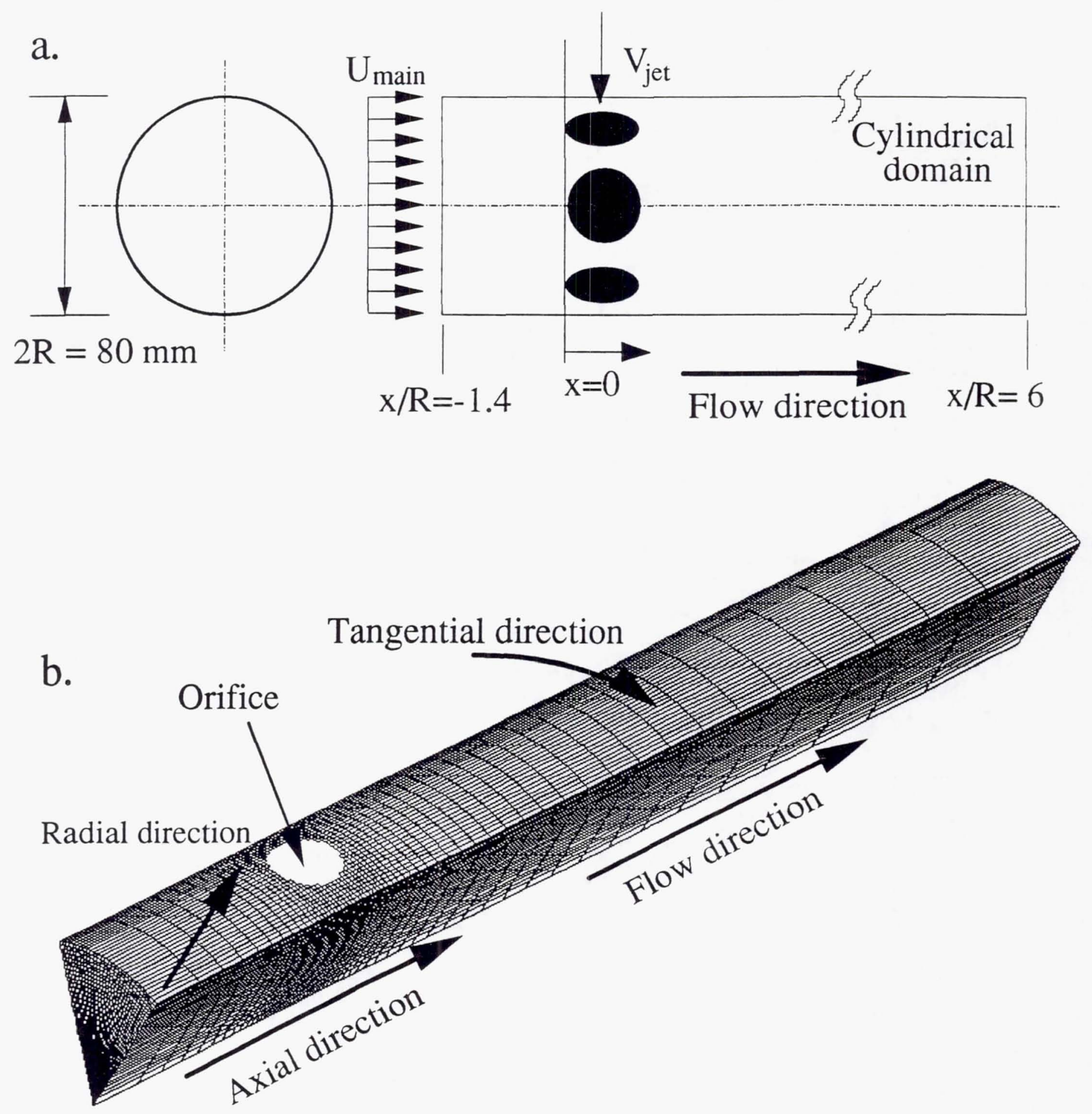

Figure 1. Depiction of (a.) geometric configuration of the mixing section and (b.) typical computational grid. 


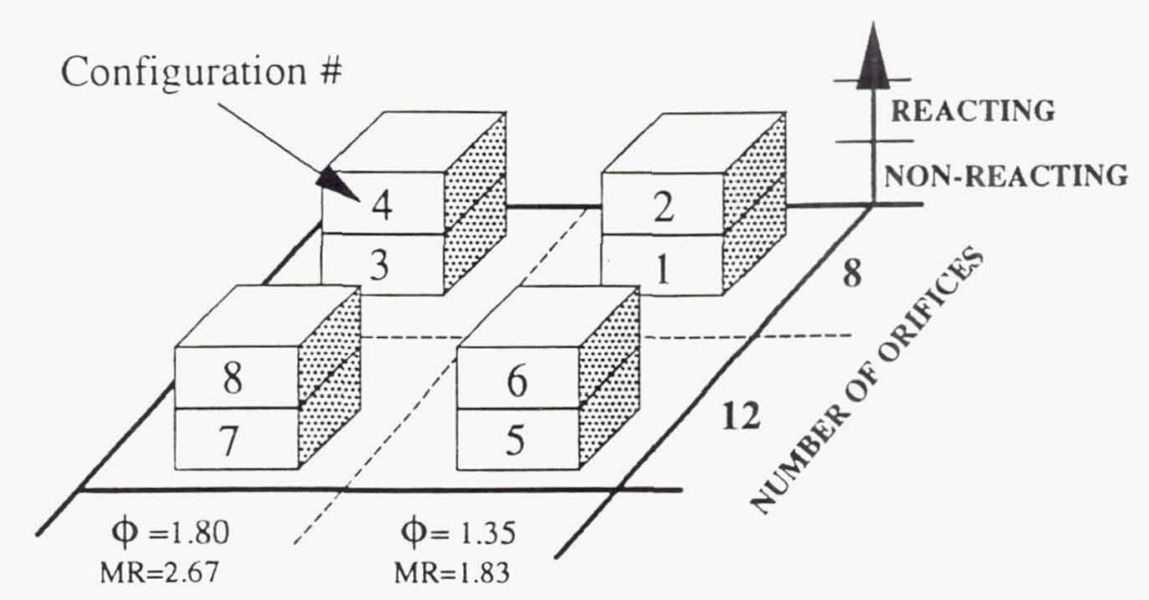

RICH ZONE EQUIVALENCE RATIO AND

MASS FLOW RATIO VARIATION

\section{Figure-2. Matrix of analyzed configurations}

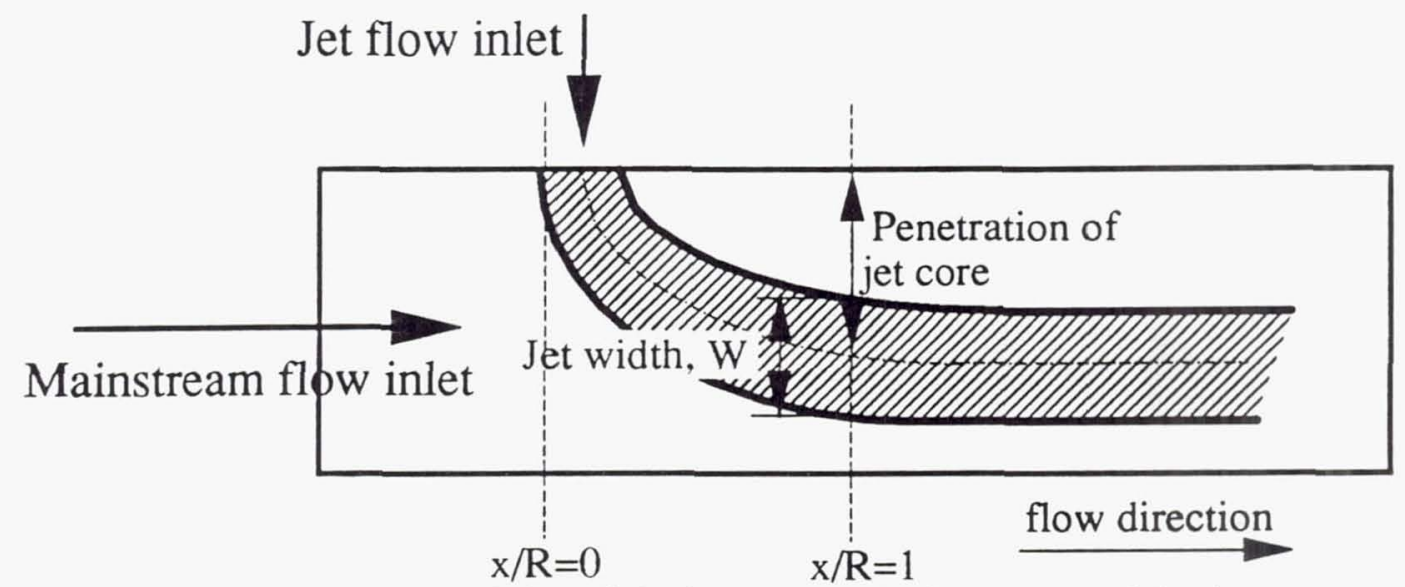

Axial-radial plane through the center of the jet

Figure-3. Jet parameter definition

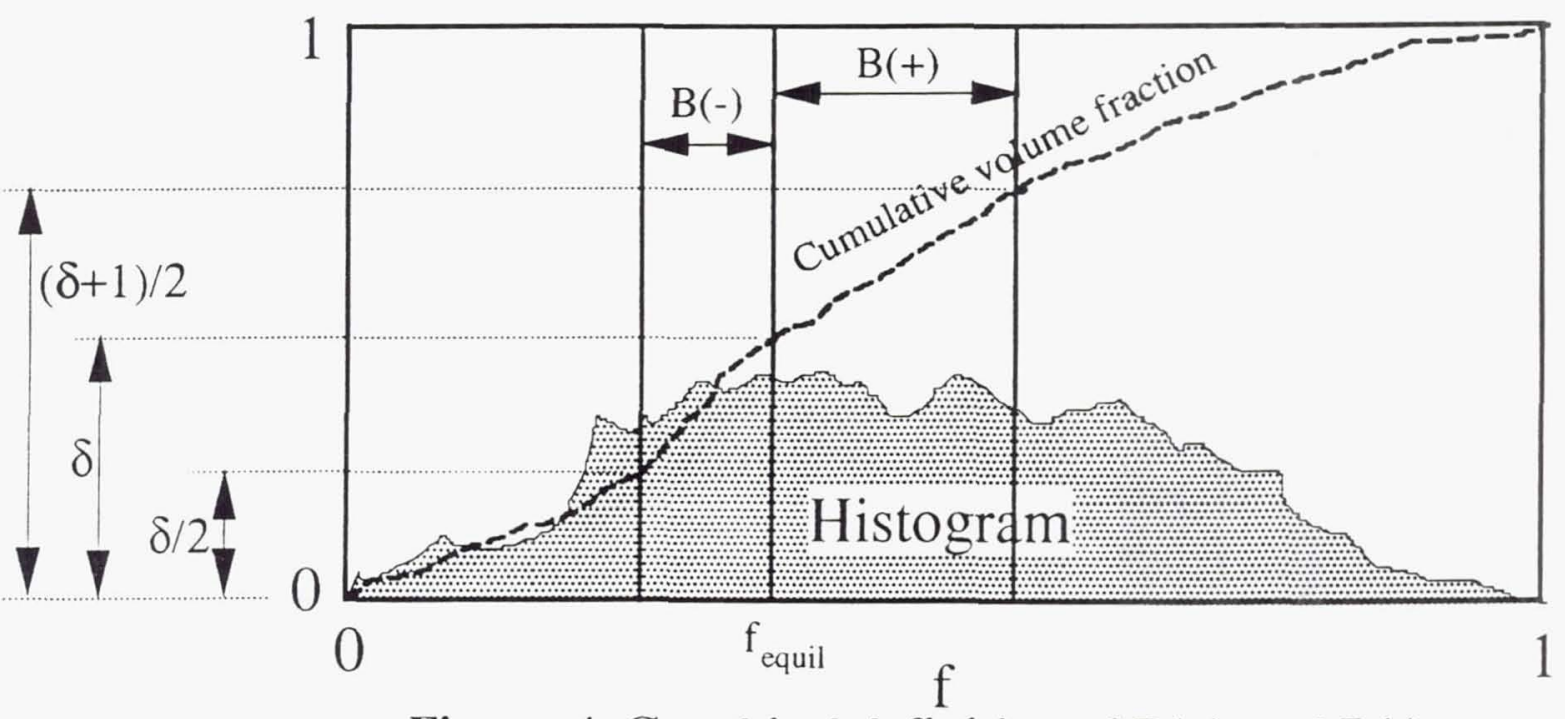

Figure-4. Graphical definition of $\mathrm{B}(+)$ and $\mathrm{B}(-)$ 
Page intentionally left blank 

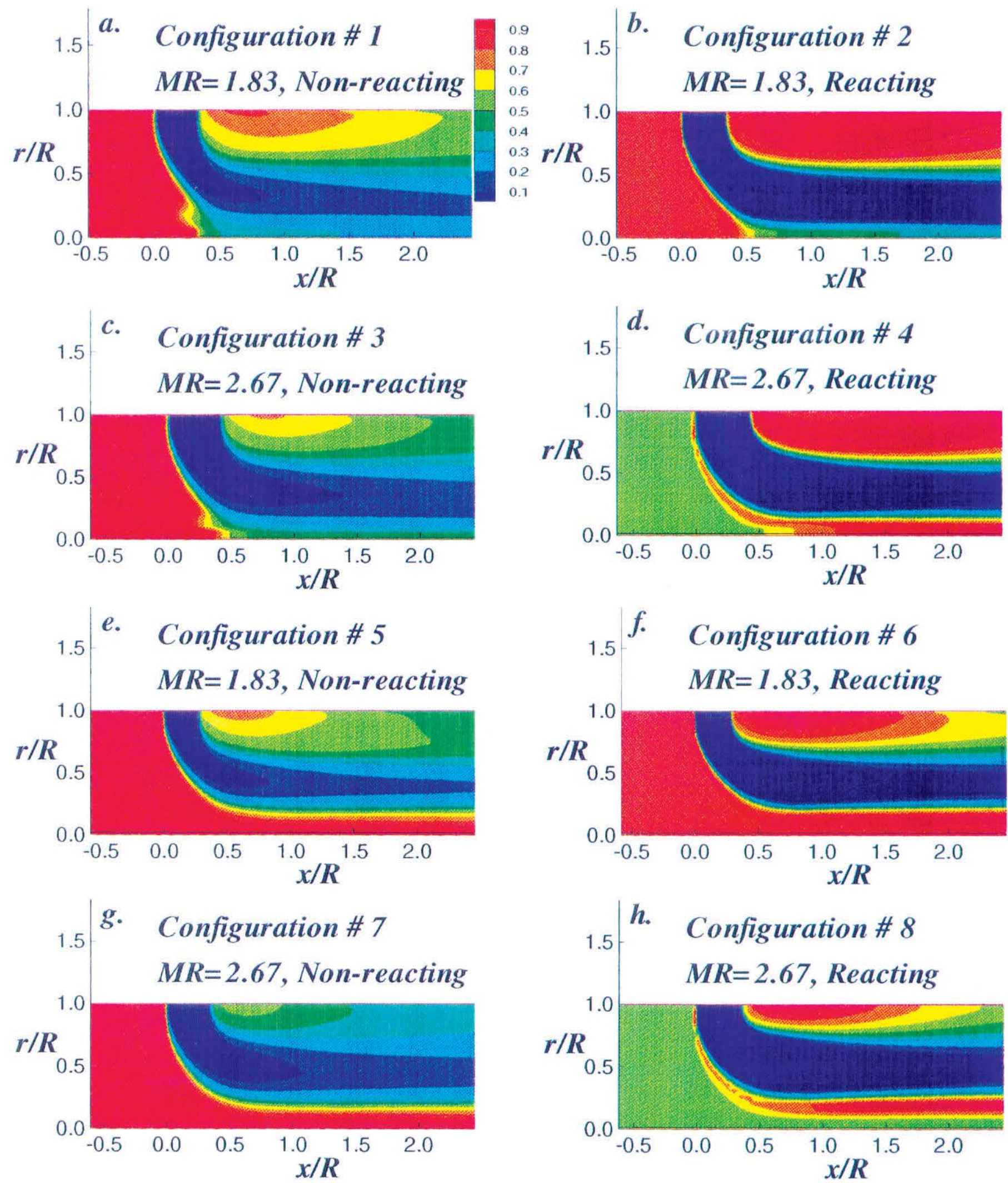

Figure-5. Normalized Temperature distribution through the center of the jet

(a., b., c., and d. ) 8 round orifices / row (e., f., g., and h. ) 12 round orifices / row

$$
\text { jet }=0
$$

mainstream $=1$ (non-react flows) stoichiometry $=I$ (react flows) 
Page intentionally left blank 
a. Configuration \# I $M R=1.83$

Non-reacting

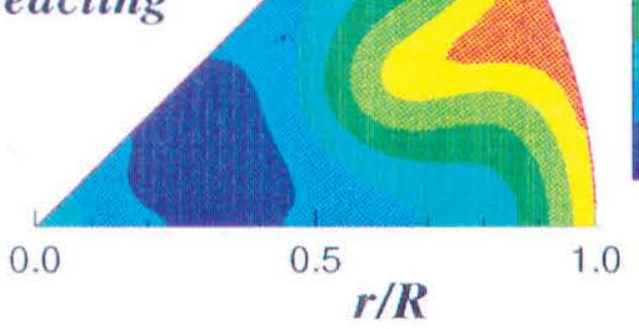

c. Configuration \# 3

$M R=2.67$

Non-reacting

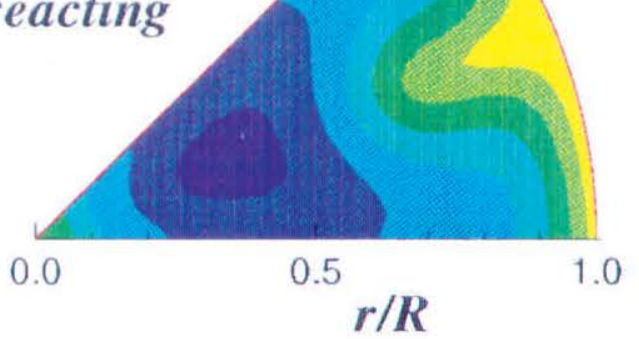

e. Configuration \# 5

$M R=1.83$

Non-reacting

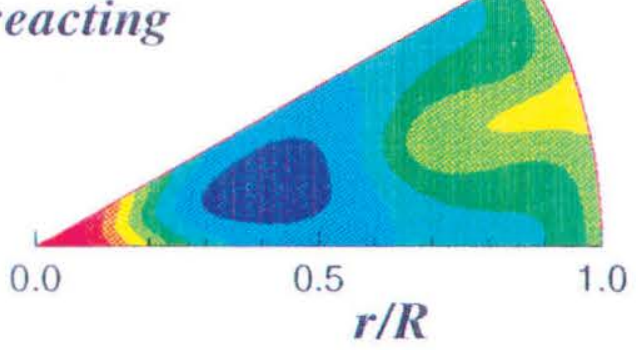

g. Configuration \# 7

$M R=2.67$

Non-reacting

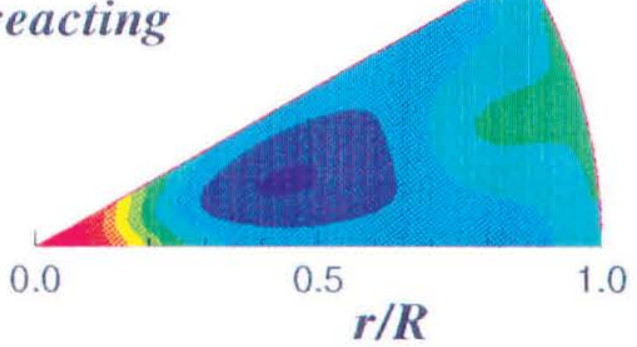

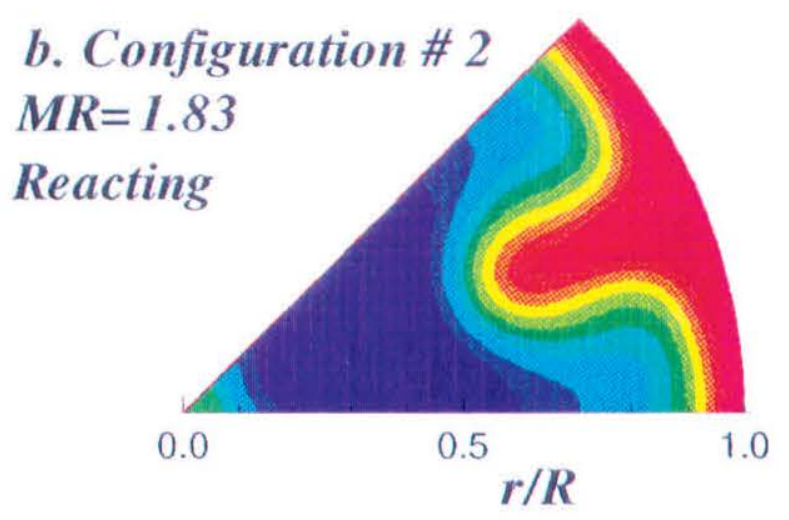

d. Configuration \# 4 $M R=2.67$

Reacting

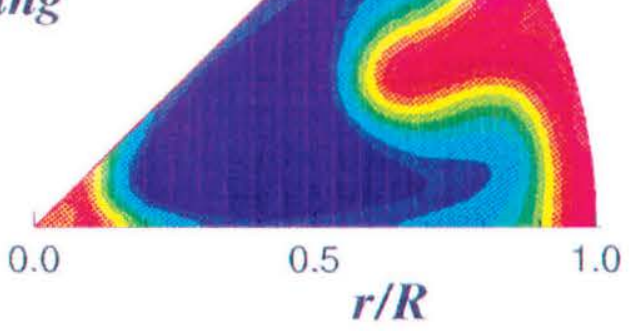

f. Configuration \# 6

$M R=1.83$

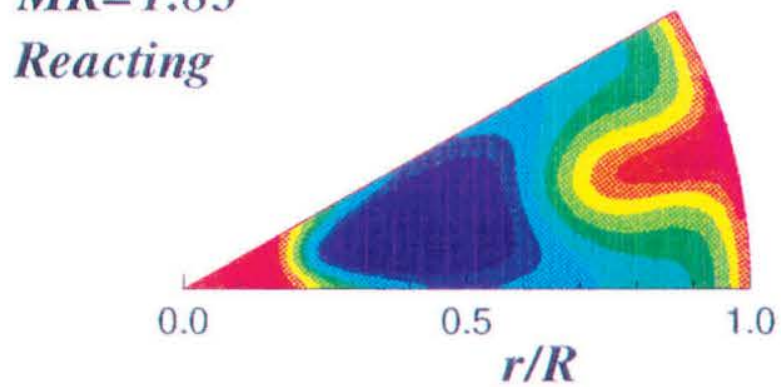

h. Configuration \# 8

$M R=2.67$

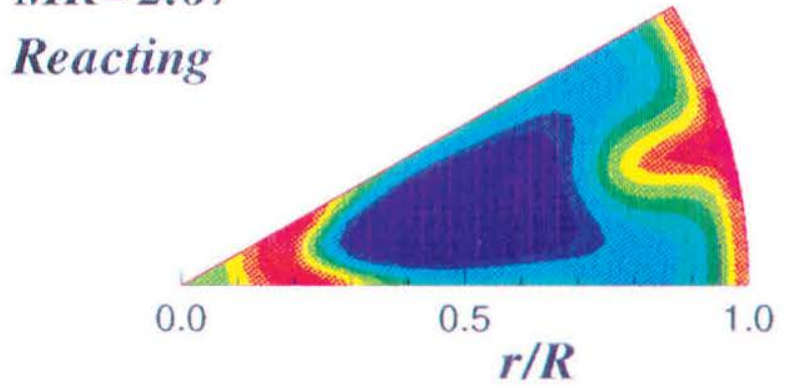

Figure-6. Normalized temperature distribution in the radial-tangential plane at $x / R=I$

(a., b., c., and d. ) 8 round orifices / row

(e., f., g., and h. ) 12 round orifices / row

$$
\text { jet }=0
$$

mainstream $=1$ (non-reacting flows) stoichiometry $=1$ (reacting flows) 
Page intentionally left blank 

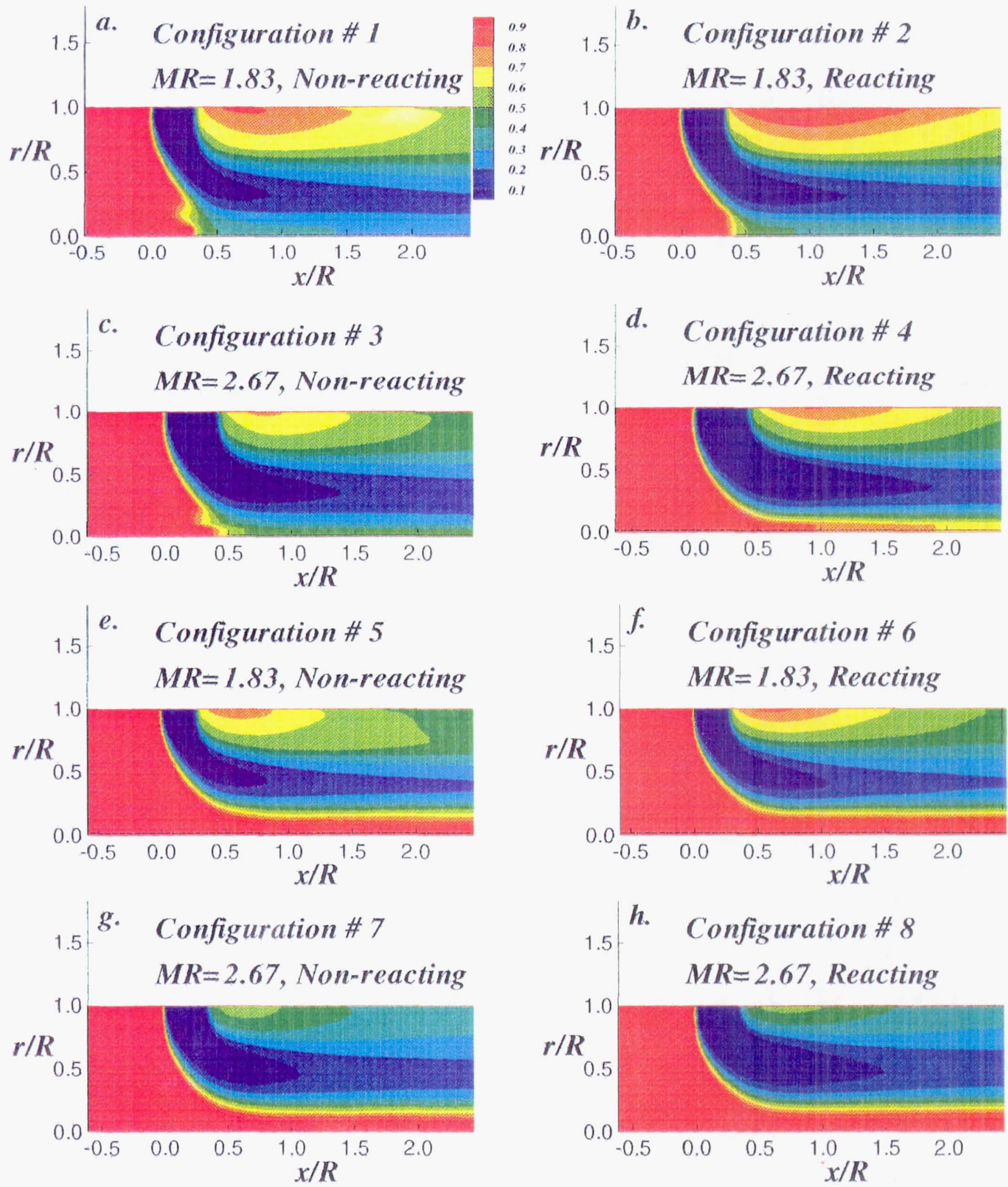

Figure-7. Normalized Temperature distribution $(f)$ (non-reacting flow) compared to the normalized equivalence ratio distribution (f) (reacting flow)-- (plane through the center of the jet)

$\left(a, b, c_{\text {. }}\right.$, and $d$, ) 8 round orifices / row $f=0$ at $T_{j e t}$ or $\phi_{j e t}$ (e., f., g., and h. ) 12 round orifices / row $f=l$ at $T_{\text {main }}$ or $\phi_{\text {main }}$ 
Page intentionally left blank 
a. Configuration \# 1

$M R=1.83$

Non-reacting

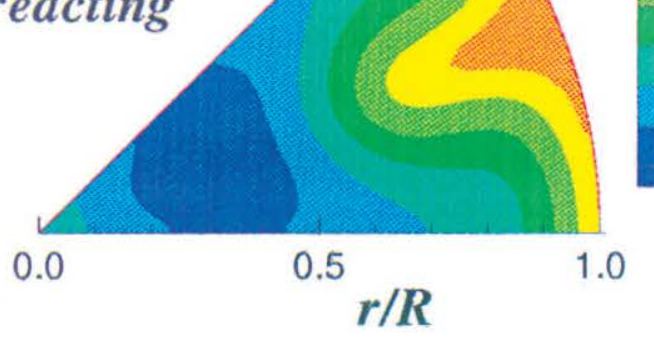

c. Configuration \# 3 $M R=2.67$

Non-reacting

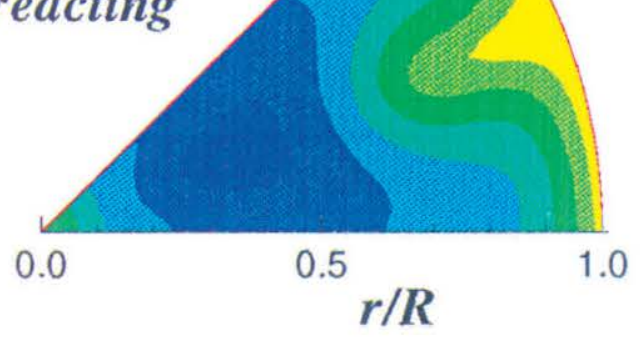

e. Configuration \# 5

$M R=1.83$

Non-reacting

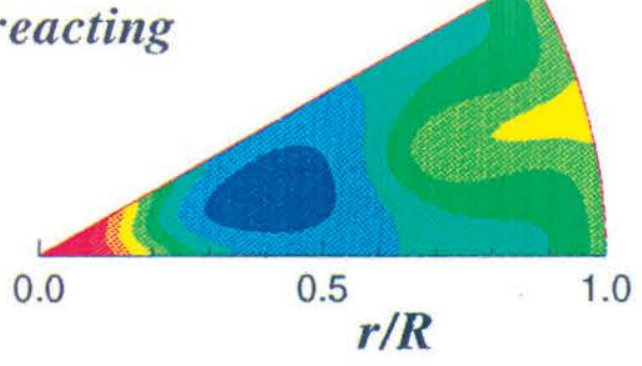

g. Configuration \# 7

$M R=2.67$

Non-reacting

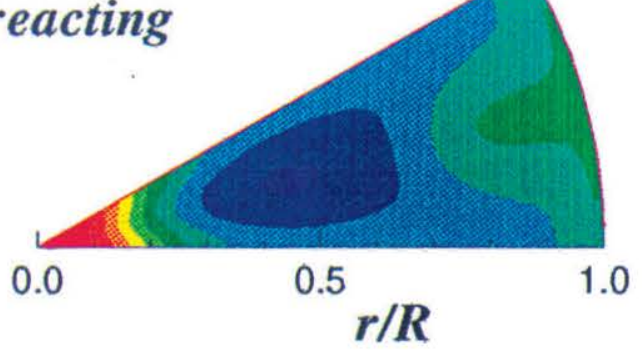

b. Configuration \# 2 $M R=1.83$

Reacting

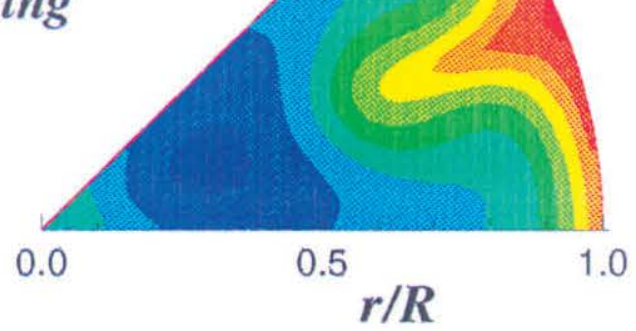

d. Configuration \# 4 $M R=2.67$

Reacting

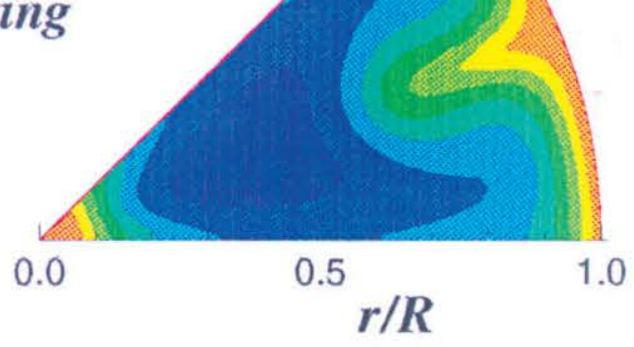

f. Configuration \# 6

$M R=1.83$

Reacting

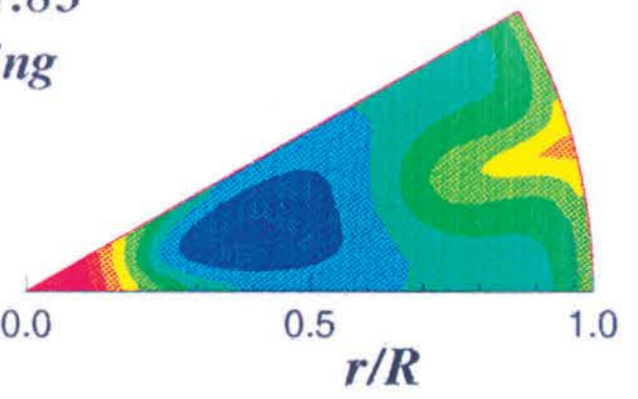

h. Configuration \# 8

$M R=2.67$

Reacting

Figure-8. Normalized temperature ( $f$ ) for the non-reacting flow compared to the normalized equivalence ratio $(f)$ for the reacting flow for radial-tangential plane at $x / R=1$

(a., b., c., and d. ) 8 round orifices / row

(e., f., g., and $h$. ) 12 round orifices / row 
Page intentionally left blank 

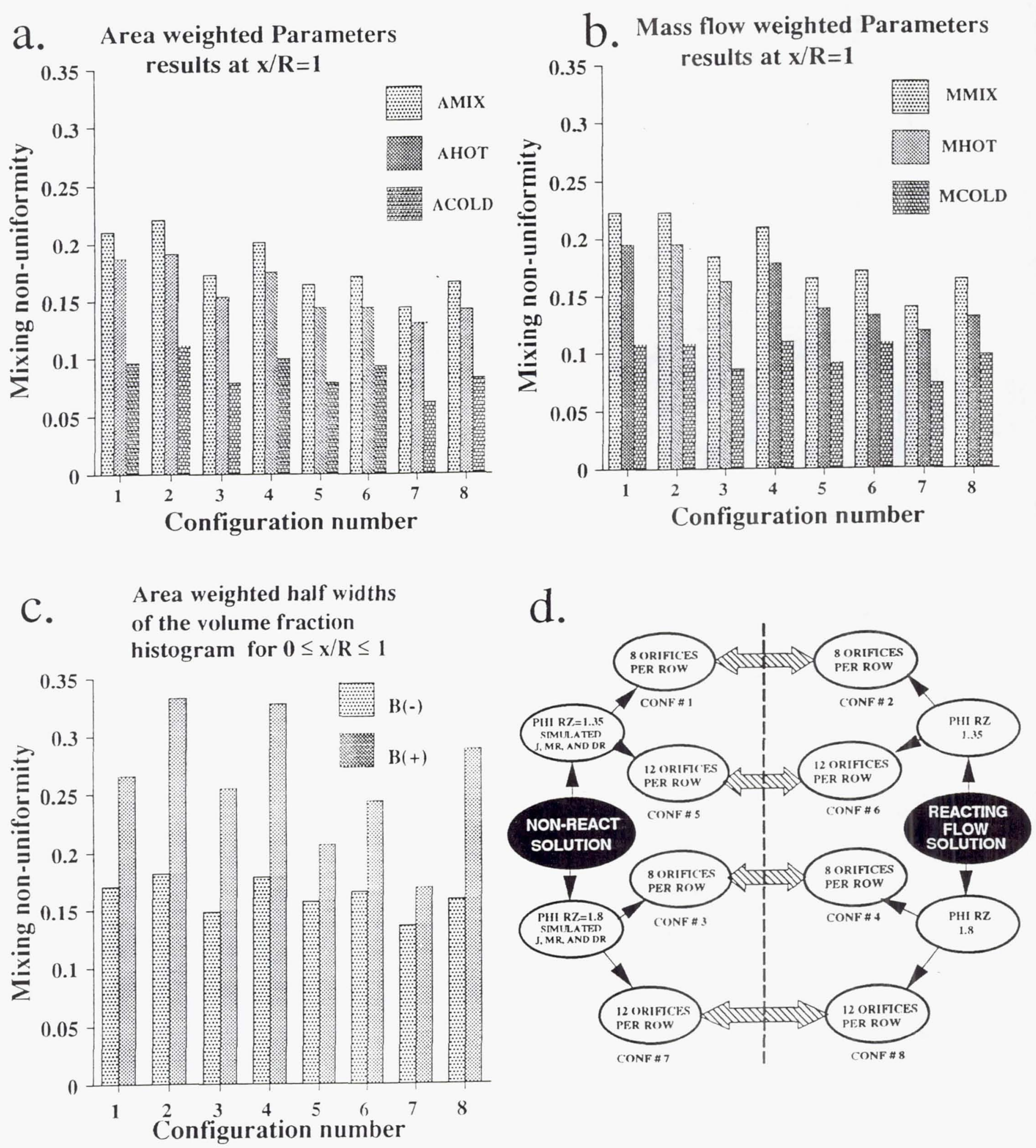

Figure-9. Mixing non-uniformity parameters (Table-3). 

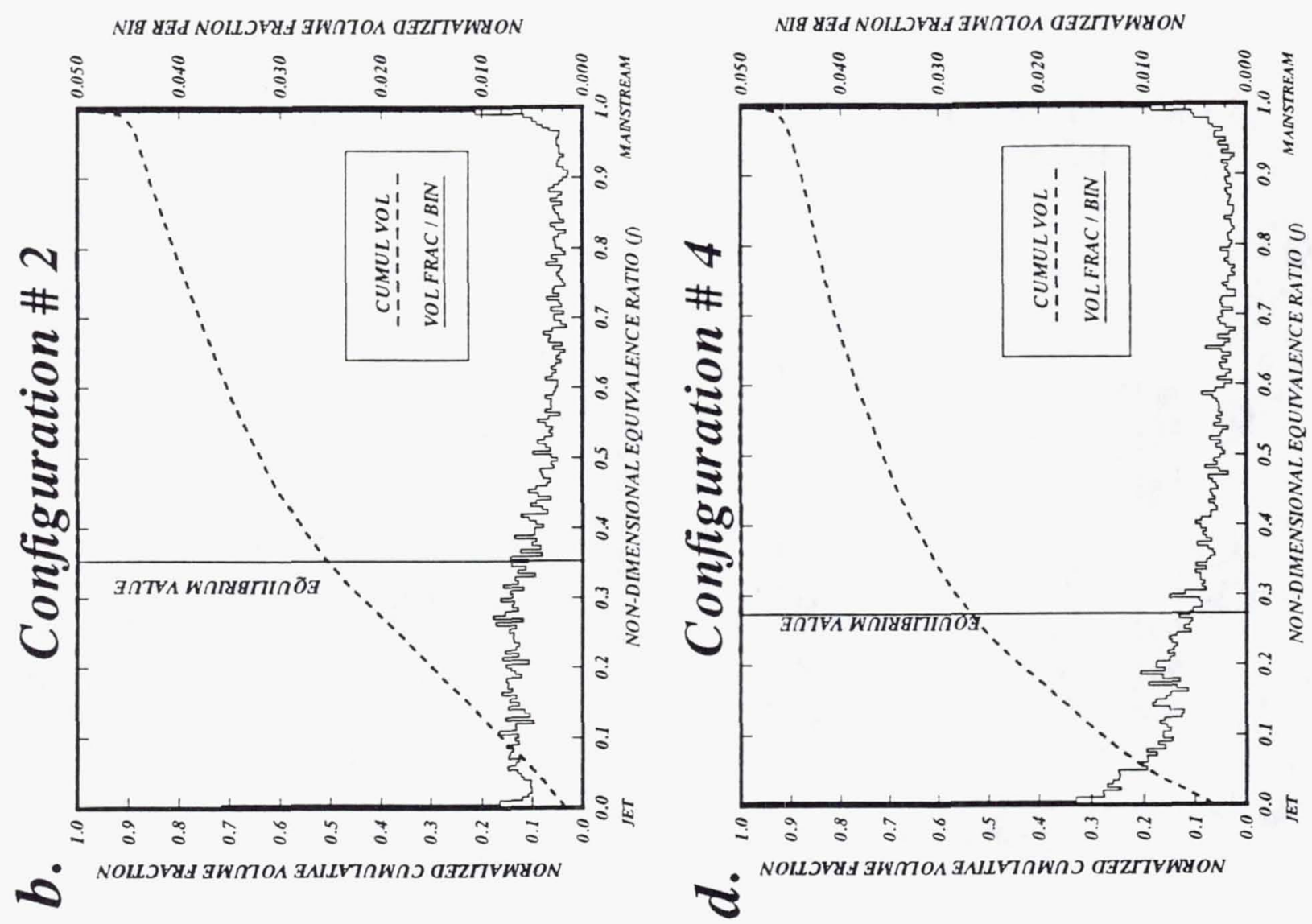

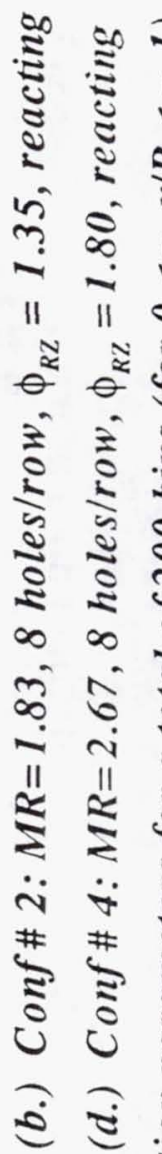
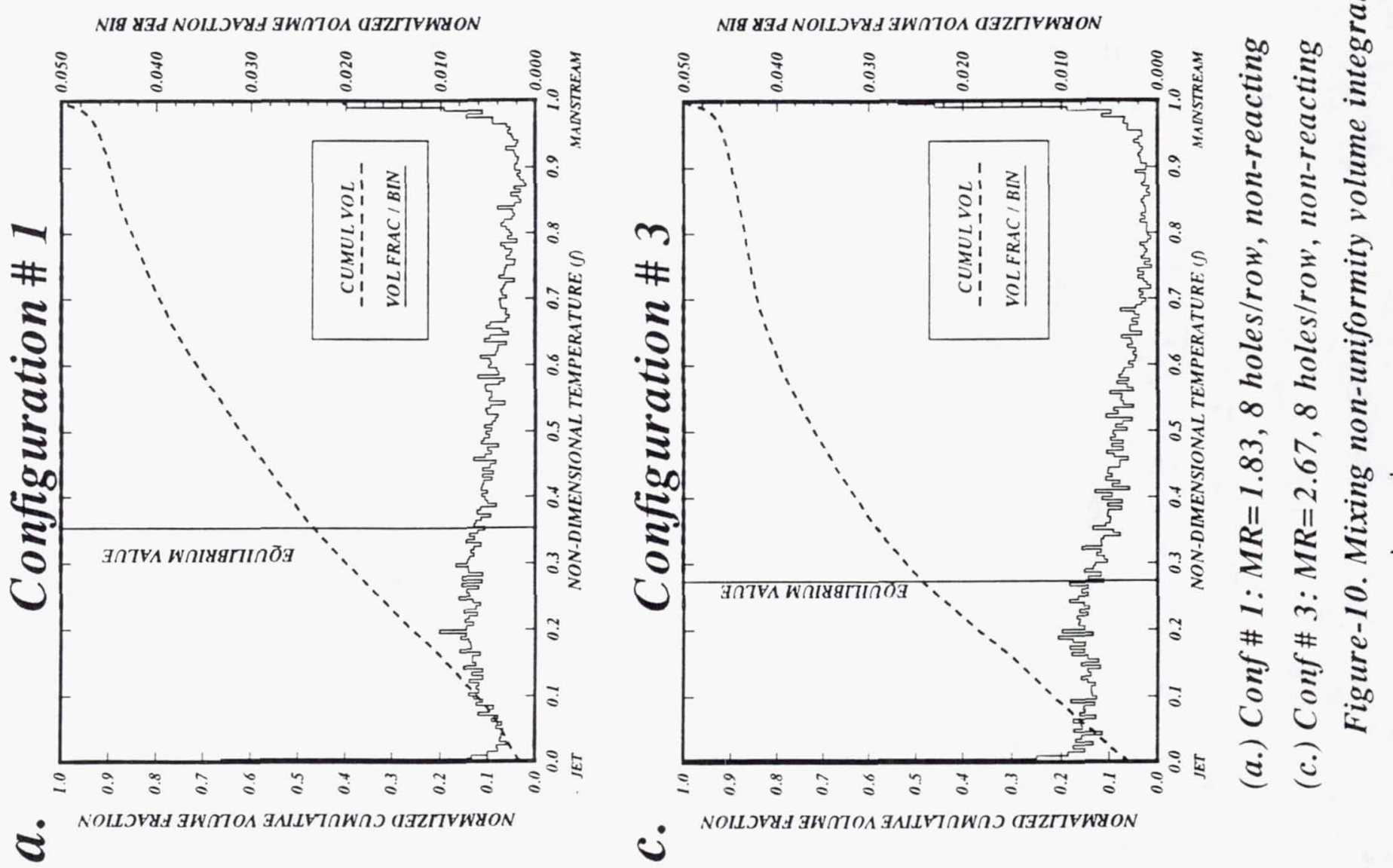

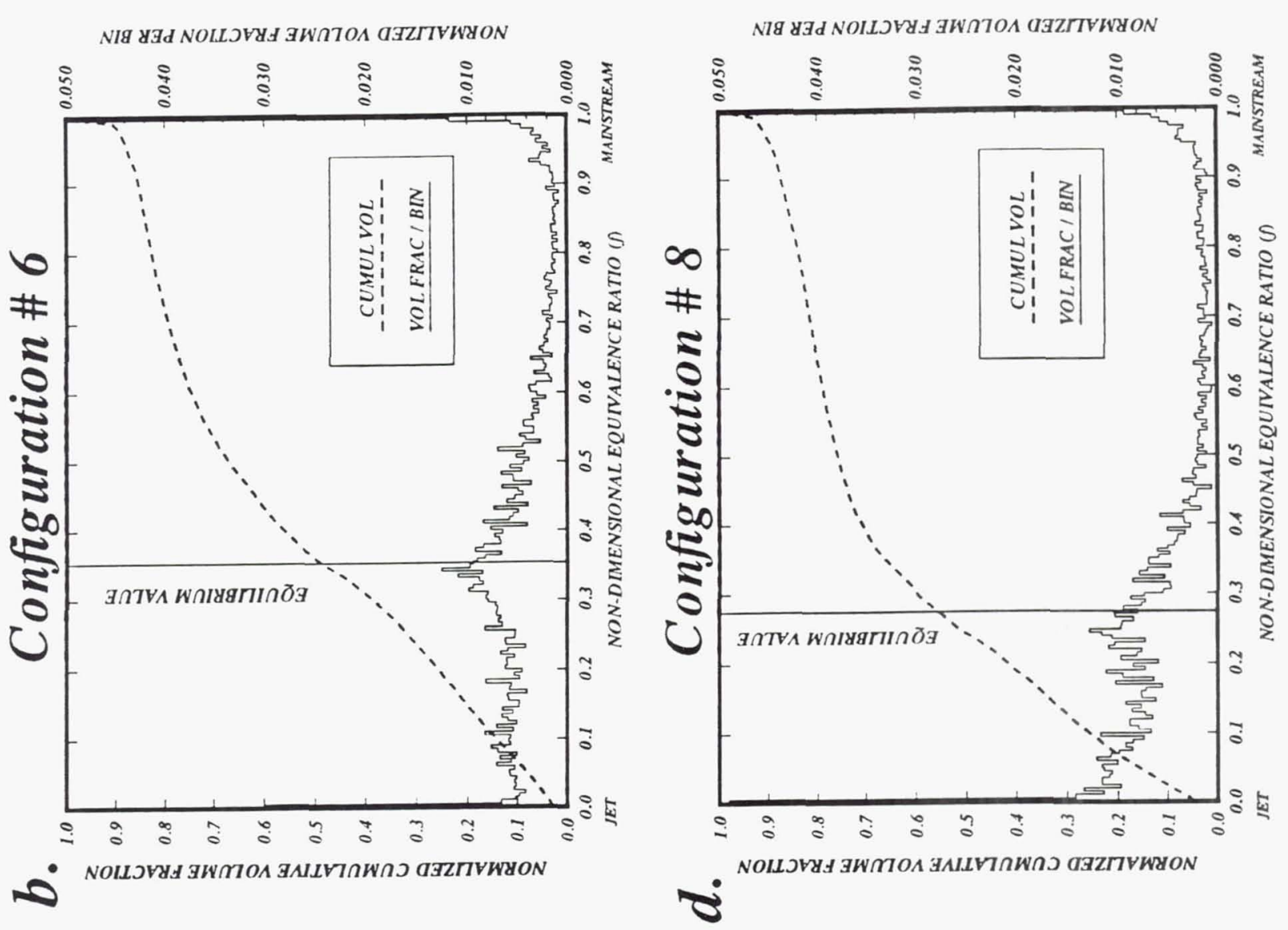

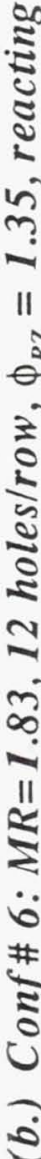
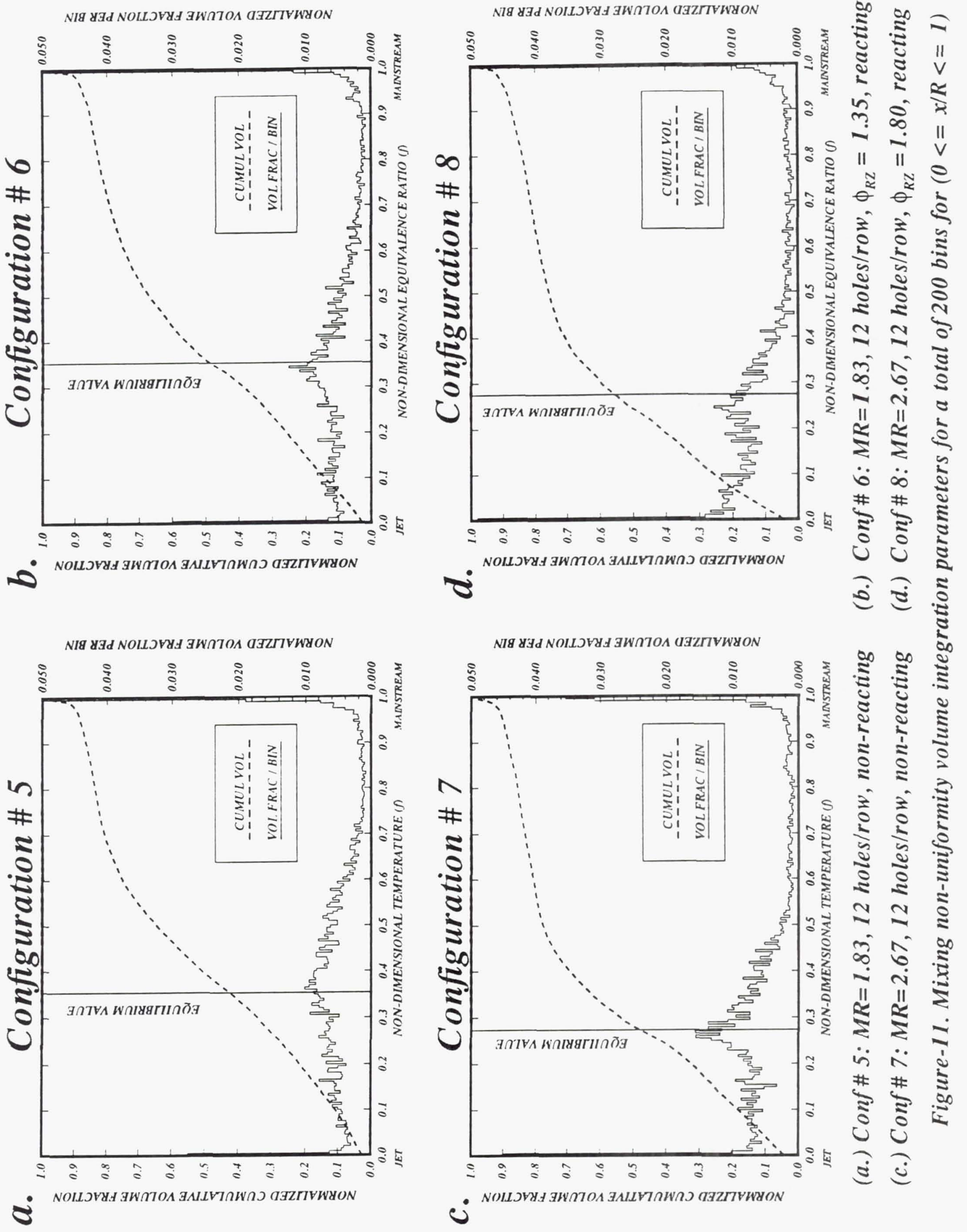


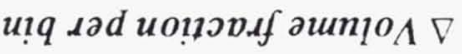

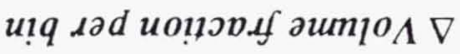
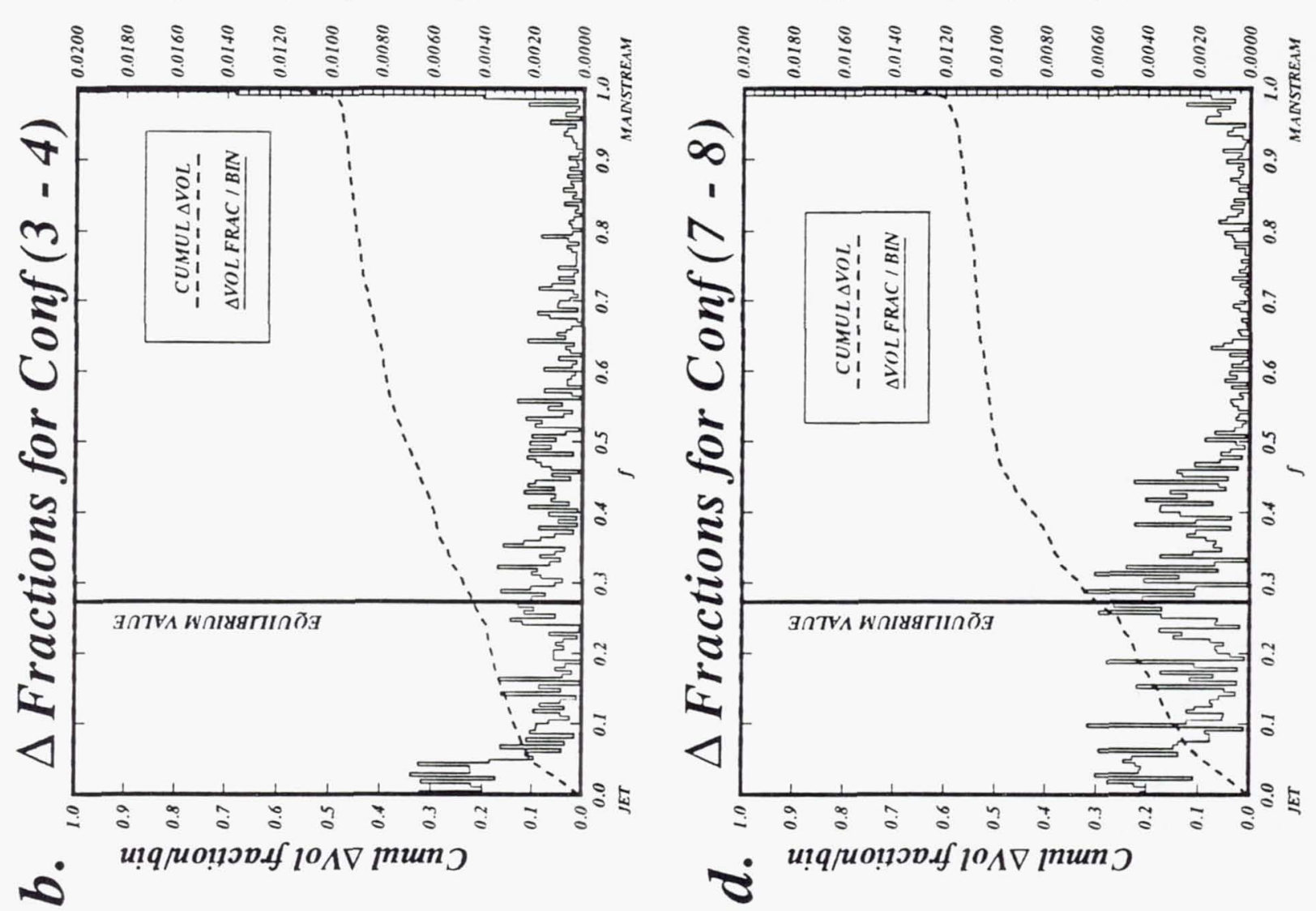

.

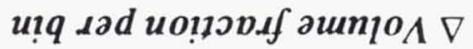
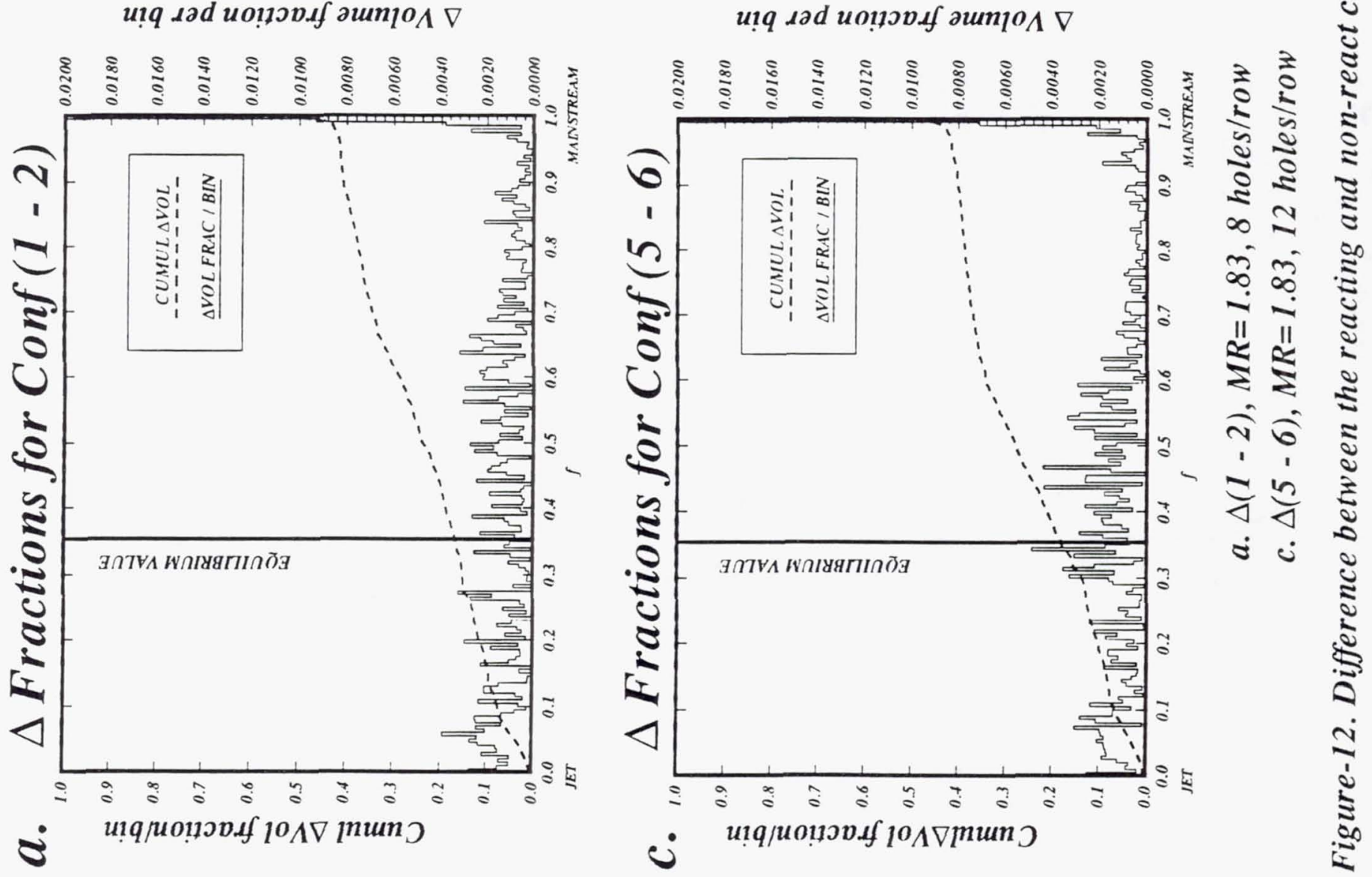

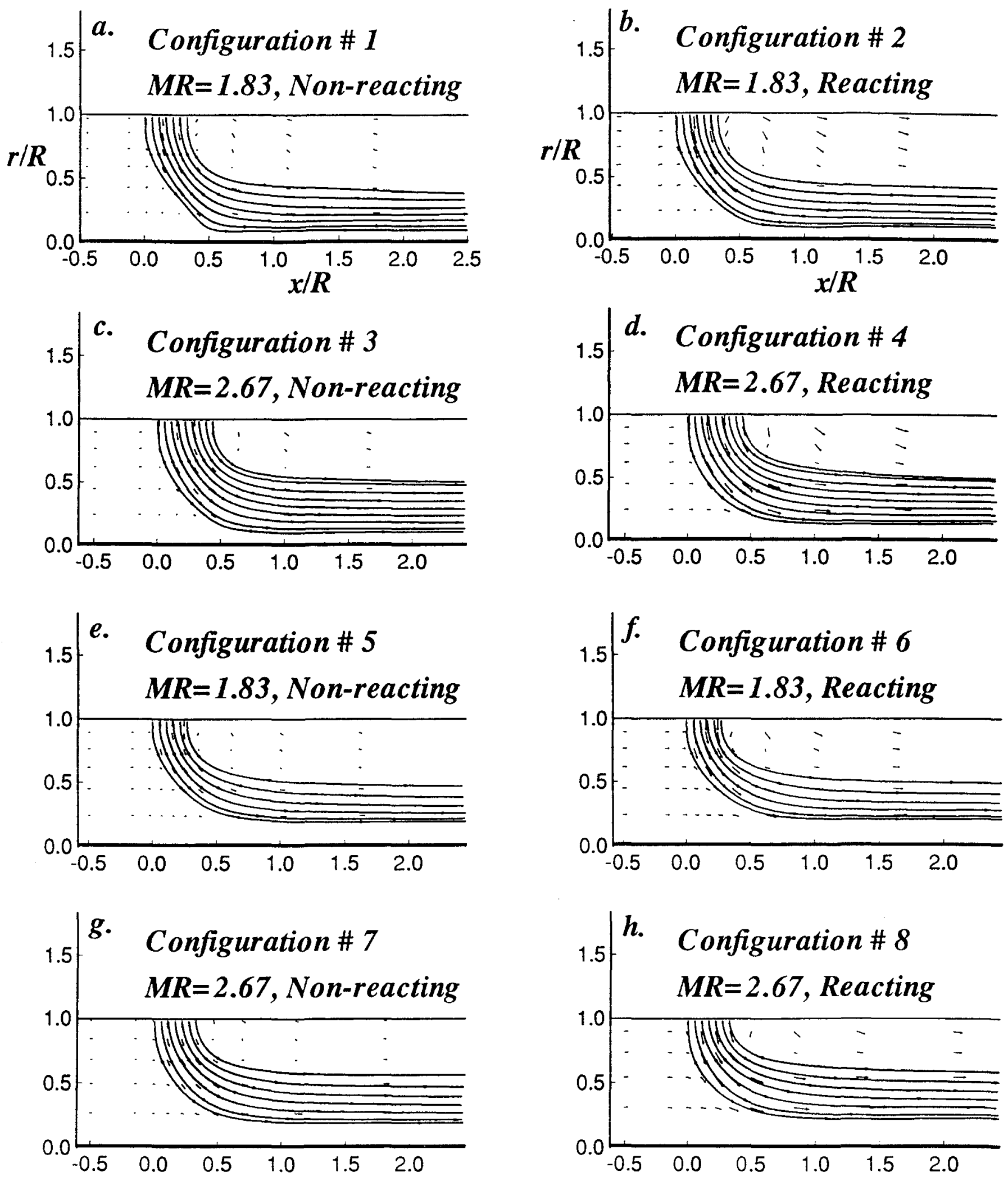

Figure-13. Jet penetration as seen through the center of the jet $(a ., b ., c .$, and $d$.$) s round orifices / row$ (e., f., g., and h. ) 12 round orifices / row 


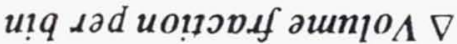

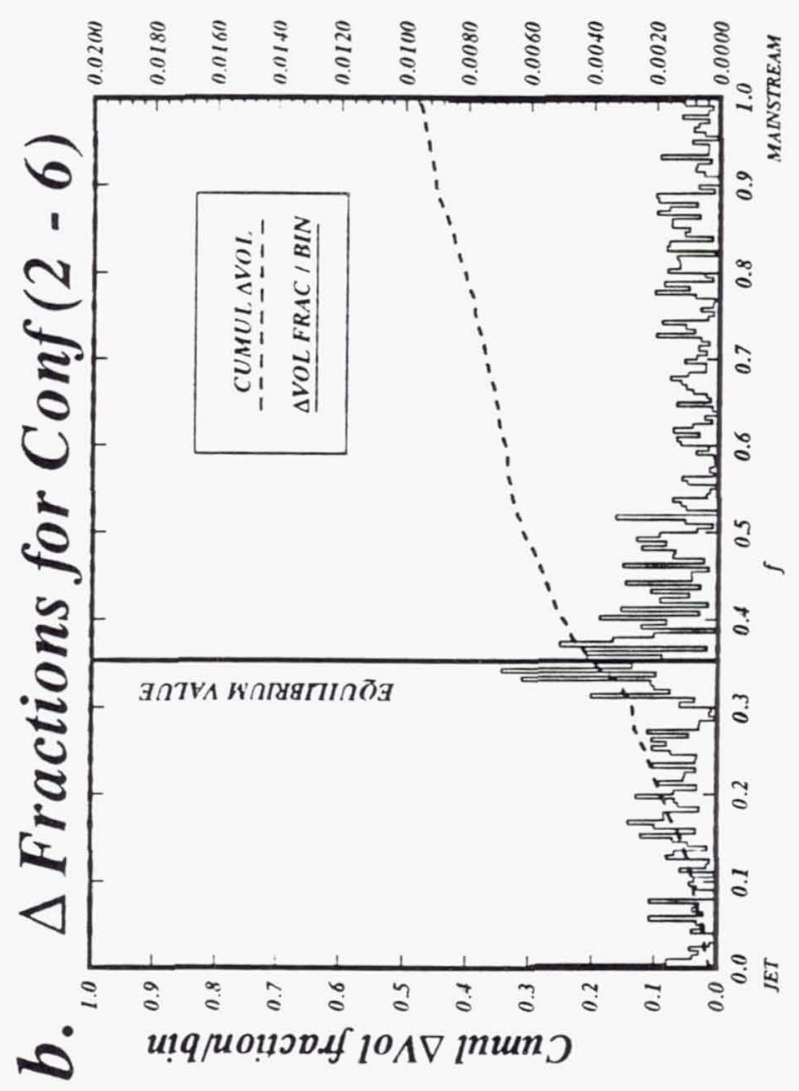

u!q גad uonjopג aum $10 \Lambda \nabla$

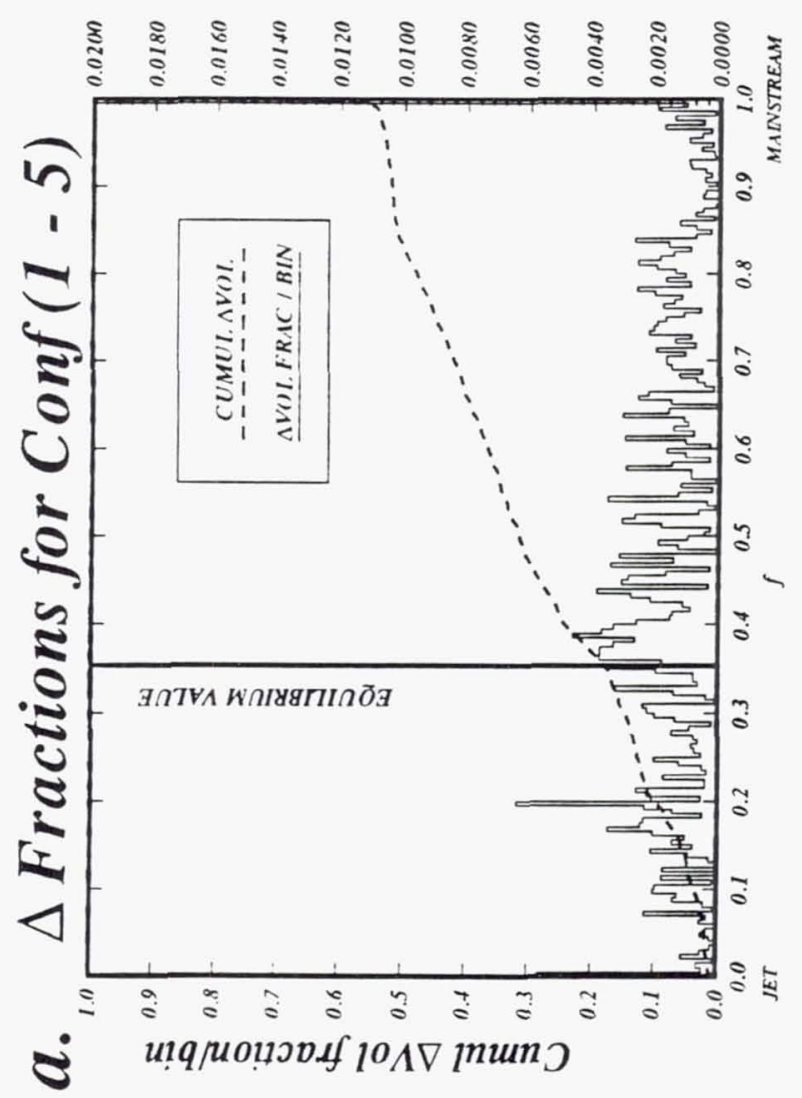

u!q dad uoupopd aum $10_{\Lambda} \nabla$

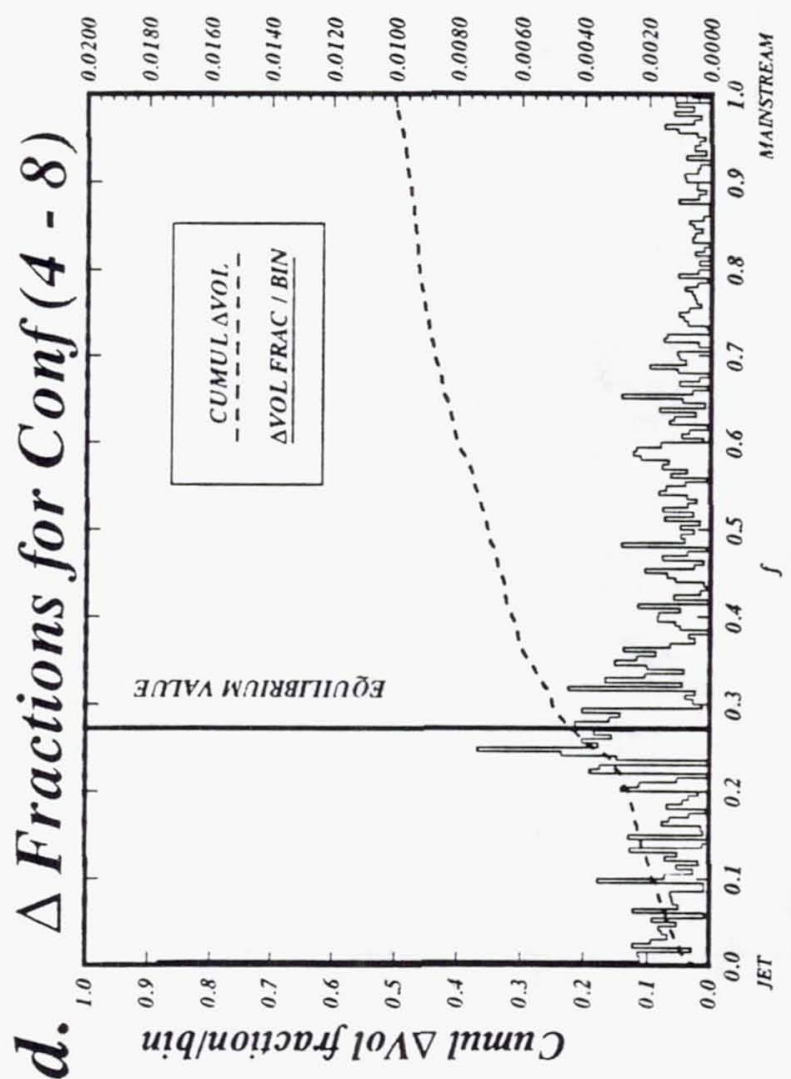

u!q גad uonpop.s aumlo $\Lambda \nabla$

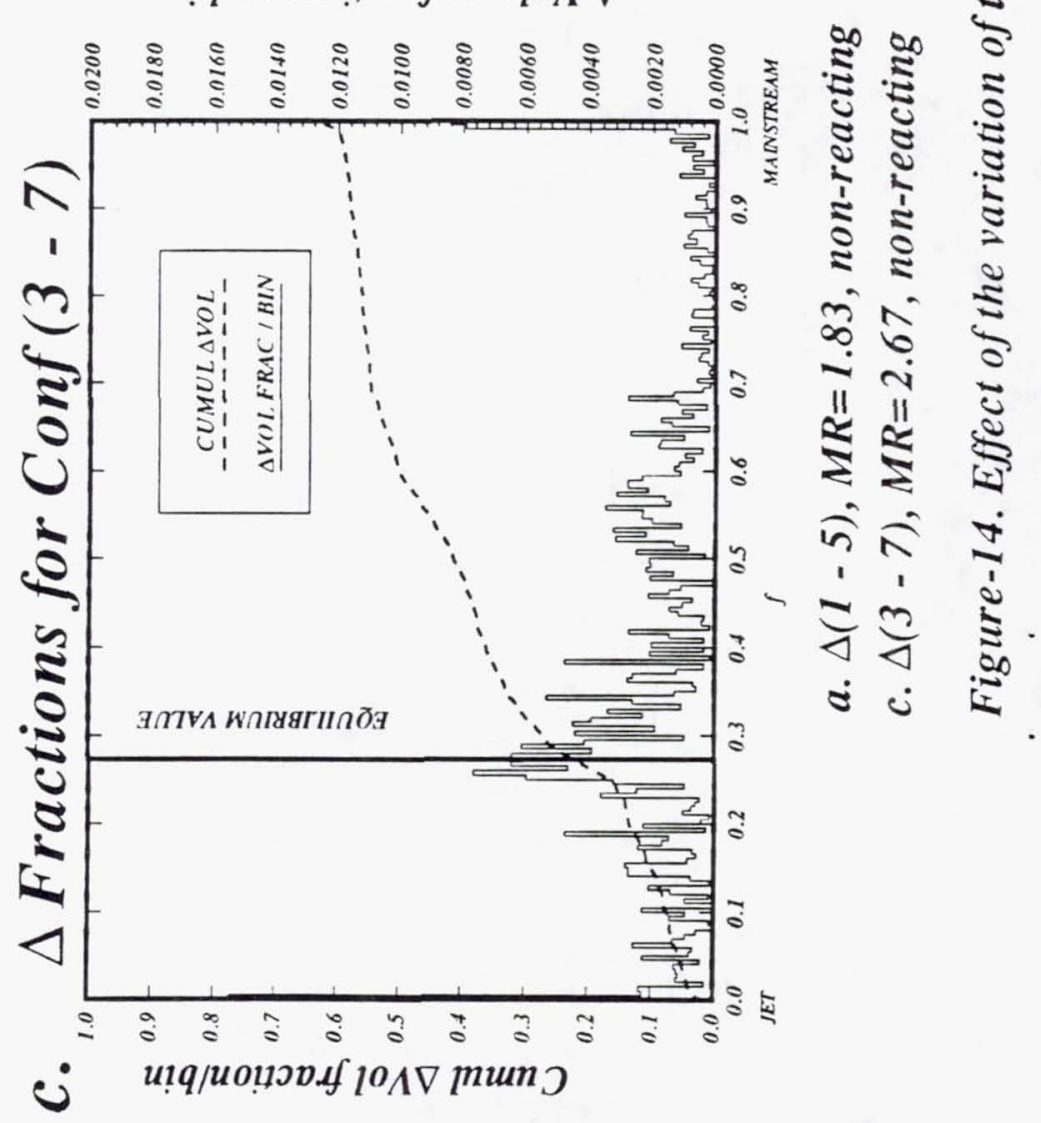




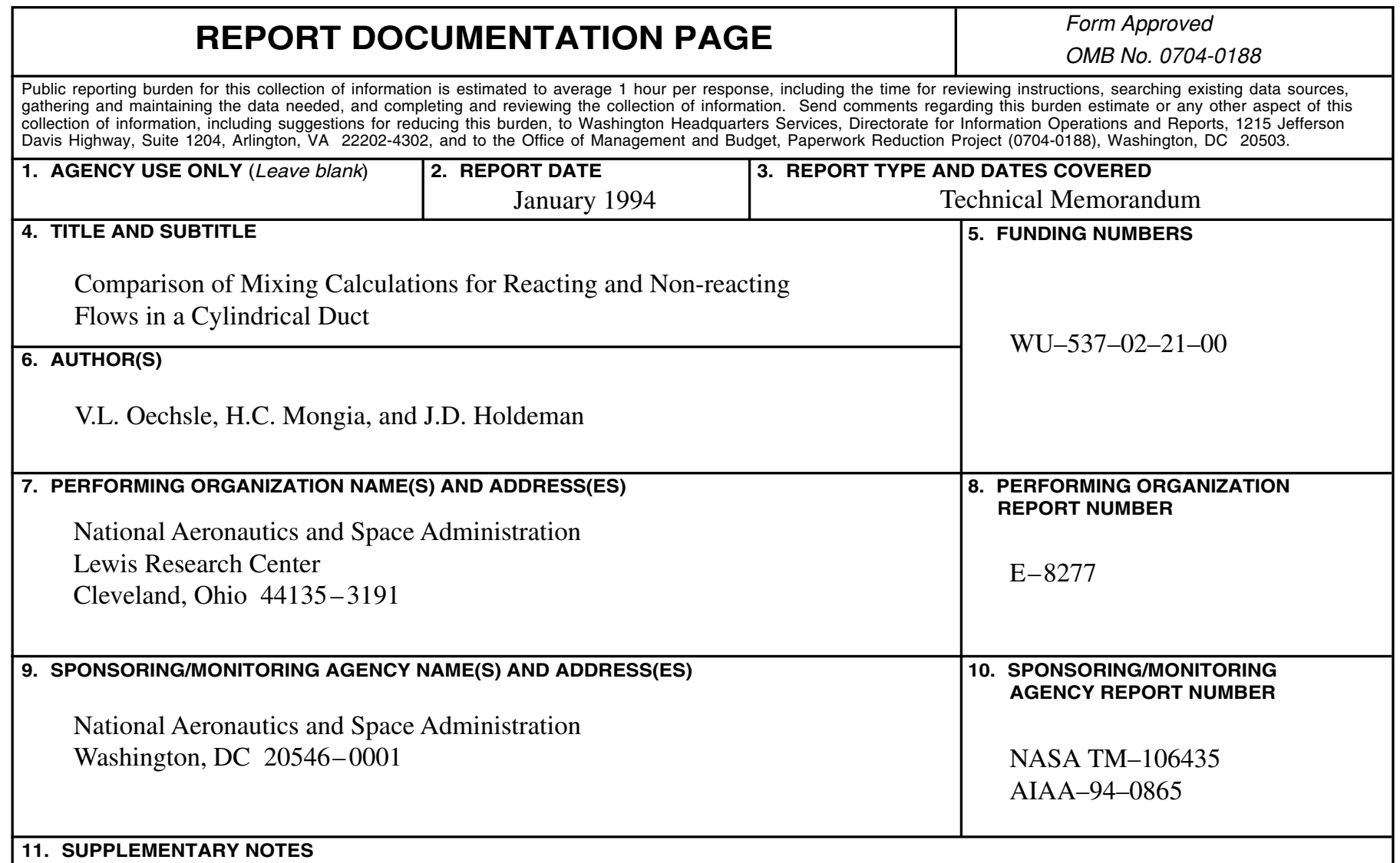

Prepared for the 32nd Aerospace Sciences Meeting and Exhibit, sponsored by the American Institute of Aeronautics and Astronautics, Reno, Nevada, January 10-13, 1994. V.L. Oechsle and H.C. Mongia, Allison Gas Turbine Division, General Motors Corporation, Indianapolis, Indiana, 46206 and J.D. Holdeman, NASA Lewis Research Center. Responsible person, J.D. Holdeman, (216) 433-5846.

\begin{tabular}{l|l}
\hline 12a. DISTRIBUTION/AVAILABILITY STATEMENT & 12b. DISTRIBUTION CODE \\
Unclassified - Unlimited & \\
Subject Category: 07 & \\
Available electronically at http://gltrs.grc.nasa.gov/GLTRS & \\
This publication is available from the NASA Center for AeroSpace Information, (301) 621-0390. &
\end{tabular}

13. ABSTRACT (Maximum 200 words)

A production 3-D elliptic flow code has been used to calculate non-reacting and reacting flow fields in an experimental mixing section relevant to a rich-burn/quick-mix/lean-burn (RQL) combustion system. A number of test cases have been run to assess the effects of the variation in the number of orifices, mass flow ratio and rich-zone equivalence ratio on the flow field and mixing rates. The calculated normalized temperature profiles for the non-reacting flow field agree qualitatively well with the normalized conserved variable isopleths for the reacting flow field indicating that non-reacting mixing experiments are appropriate for screening and ranking potential rapid mixing concepts. For a given set of jet momentum-flux ratio, mass flow ratio, and density ratio (J, MR, and DR), the reacting flow calculations show a reduced level of mixing compared to the non-reacting cases. In addition, the rich-zone equivalence ratio has noticeable effect on the mixing flow characteristics for reacting flows.

\begin{tabular}{|c|c|c|c|}
\hline 14. SUBJECT TERMS & & & $\begin{array}{c}\text { 15. NUMBER OF PAGES } \\
28\end{array}$ \\
\hline VSN 7540-01-280-5500 & & & $\begin{array}{l}\text { ndard Form } 298 \text { (Rev. 2-89) } \\
\text { cribed by ANSI Std. Z39-18 } \\
102\end{array}$ \\
\hline
\end{tabular}




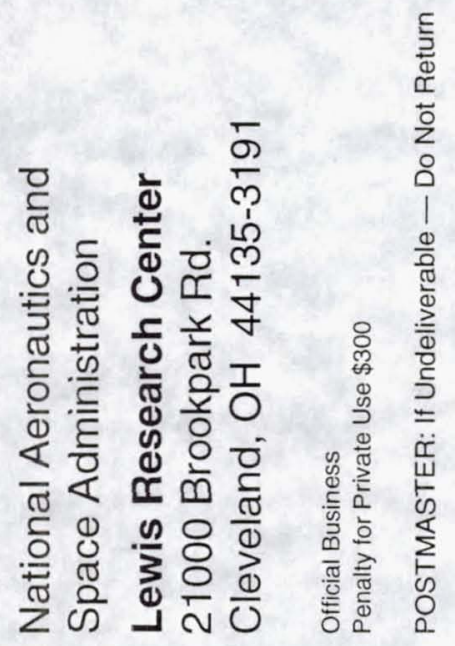

